\title{
Biowaste-derived carbon black applied to polyaniline-based high-performance supercapacitor microelectrodes: Sustainable materials for renewable energy
}

applications

Sumita

Gowra Raghupathy Dillip

Suman Nandy ${ }^{\mathrm{a}, ~ *}$

s.nandy@fct.unl.pt, snandy ju@yahoo.co.in

Arghya Narayan Banerjee ${ }^{\mathrm{b}, * *}$

arghya@ynu.ac.kr

Ana Pimentel ${ }^{\mathrm{a}}$

Sang Woo Joo

Rodrigo Martins ${ }^{a}$

Elvira Fortunato ${ }^{\mathrm{a}, * * *}$

emf@fct.unl.pt

ai3N/CENIMAT, Department of Materials Science, Faculty of Science and Technology, Universidade NOVA de Lisboa and CEMOP/UNINOVA, Campus de Caparica, 2829-516, Caparica, Portugal

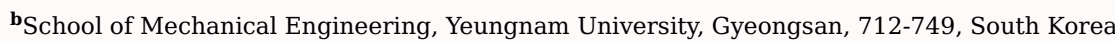

${ }^{*}$ Corresponding author.

${ }^{* *}$ Corresponding author.

${ }^{* * *}$ Corresponding author

Abstract

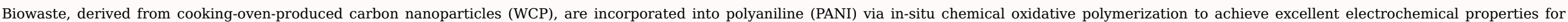

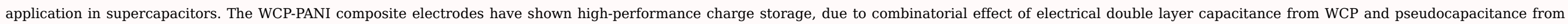

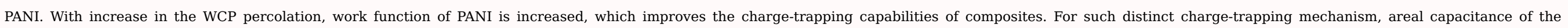

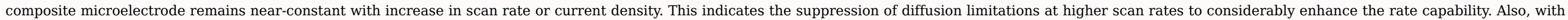

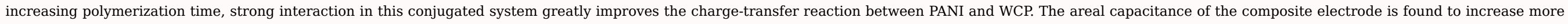

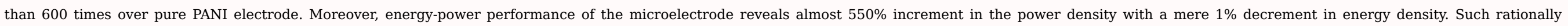

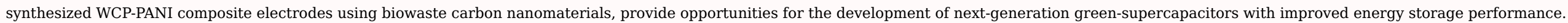

Keywords: Carbon materials; Biowastes; Polyaniline; Supercapacitors; Sustainable materials

\section{Introduction}

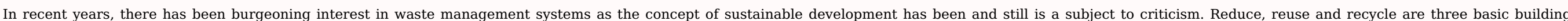




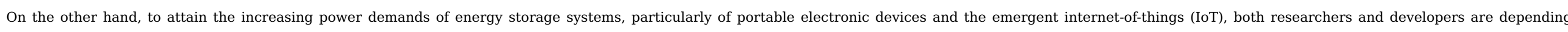

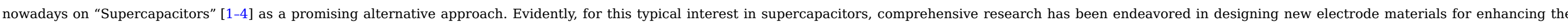

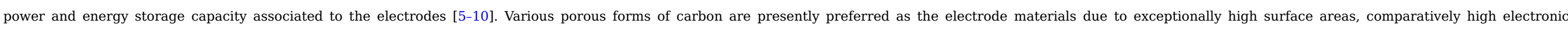

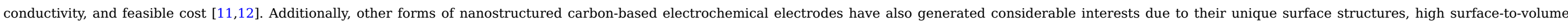
ratios, and size-dependent physical/chemical properties etc., all of which have led these active materials into higher utilization for superior electrochemical performance [13,14].

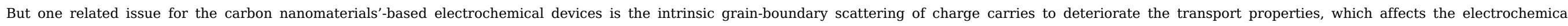

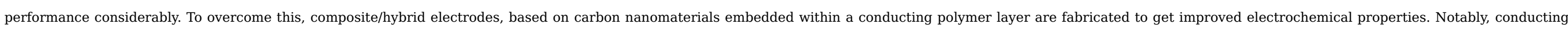

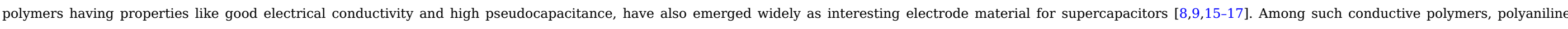

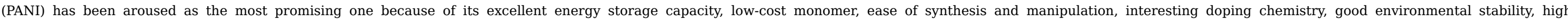

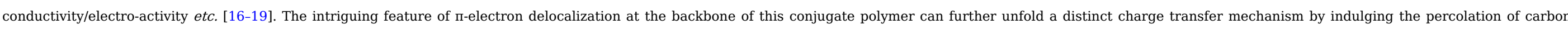

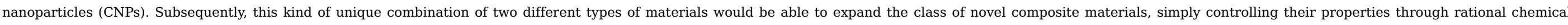

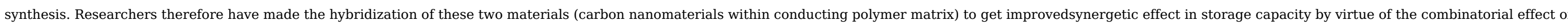

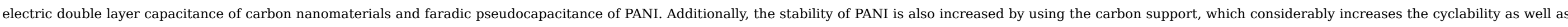

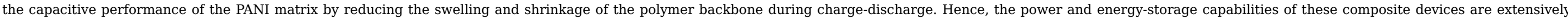
related with both physical and chemical characteristics of these hybrid electrodes.

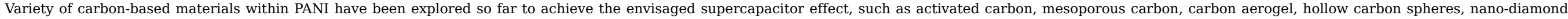

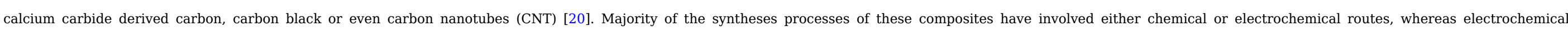

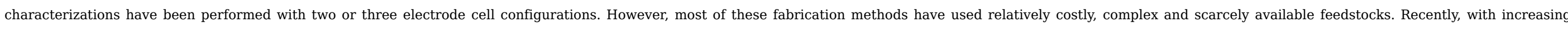

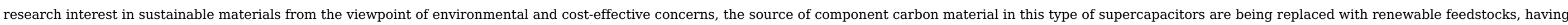

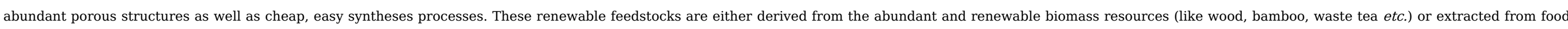

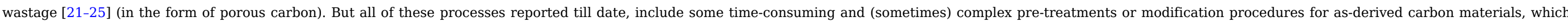
again involve some resources and chemicals (especially strong acids), that are costly and can affect the properties of the materials.

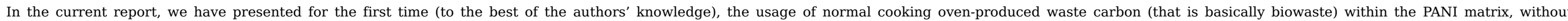

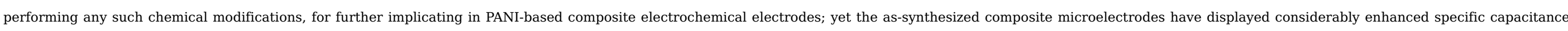

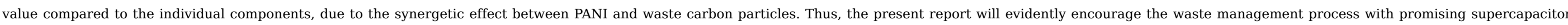
application as an added advantage.

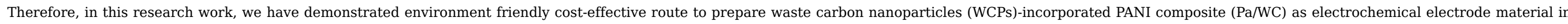

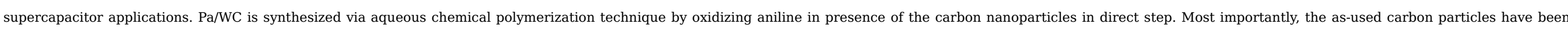

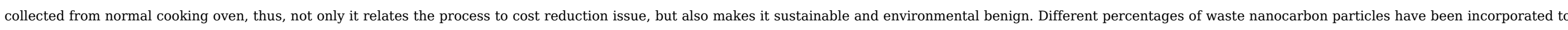

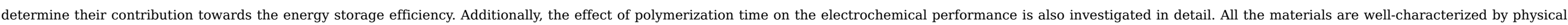

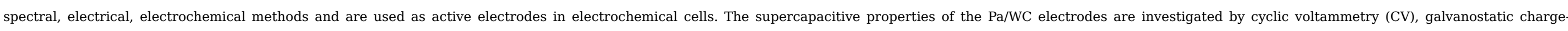

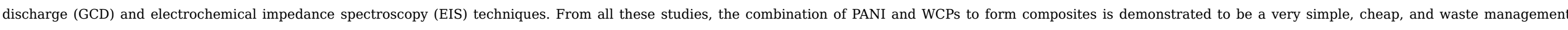

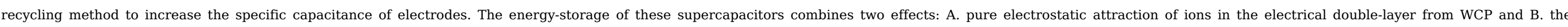

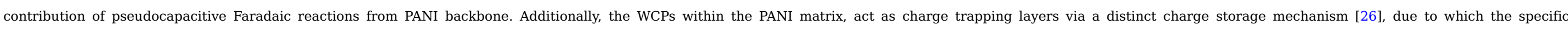




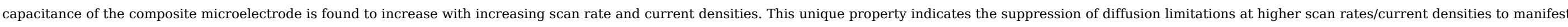

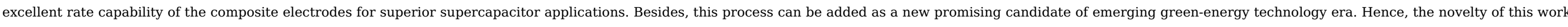

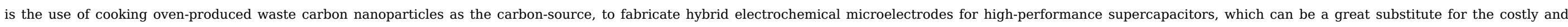
unsustainable source materials, thus stepping towards the green energy-technology.

\section{Experimental Section}

\subsection{Materials}

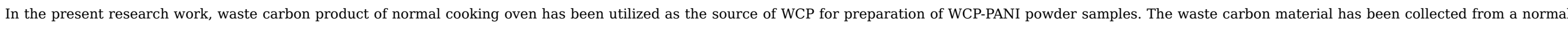

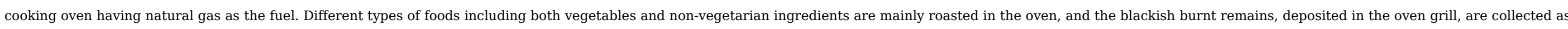

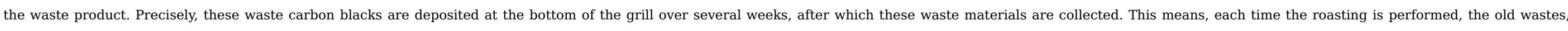

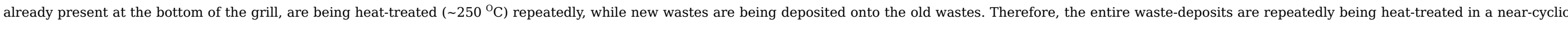

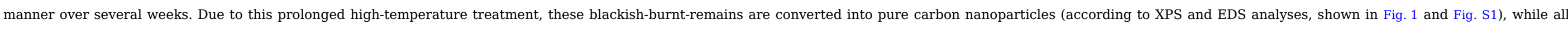
impurities are being oxidized out.
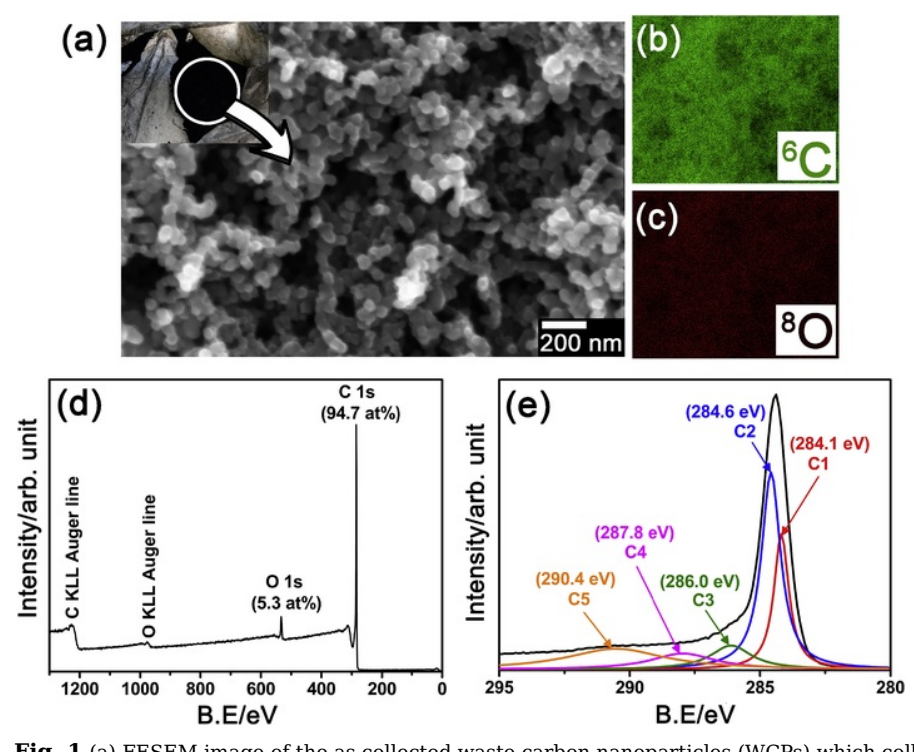

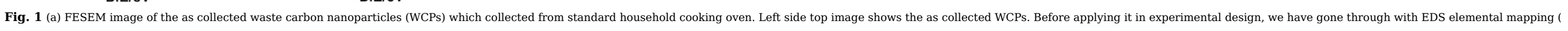
and c) and XPS survey and C $1 s$ high-resolution spectral analyses ( $\mathrm{d}$ and e), respectively, of the WCPs. The study confirms the wastage carbon products collected from the oven are pure carbon material.

\section{alt-text: Fig. 1}

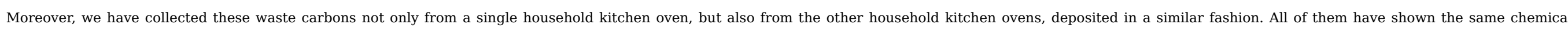

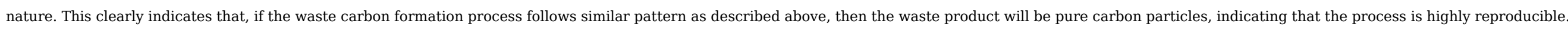

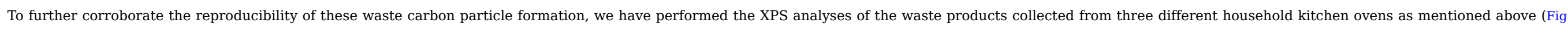

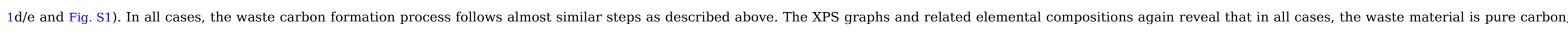

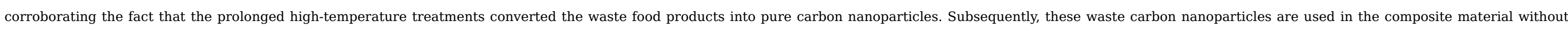
performing any pre-treatment process. 


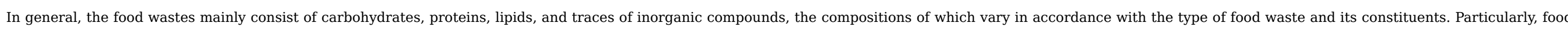

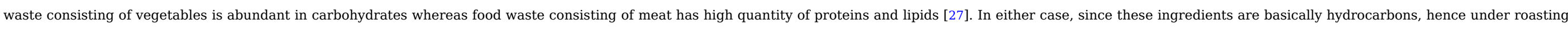
at high temperatures over a long period of time, these waste foods convert into carbon particles.

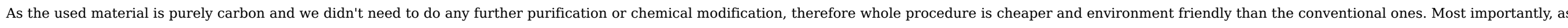

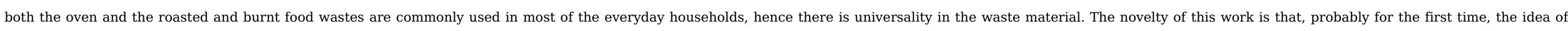
using this food waste product in practical supercapacitive applications is pursued, and therefore, the microstructural and compositional analysis is performed for potential usability in electrochemical devices.

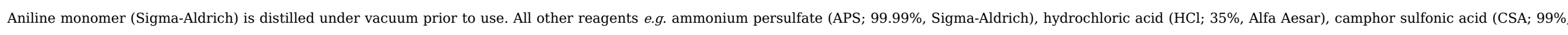

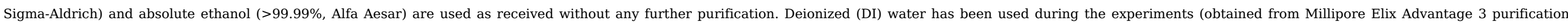
system).

\subsection{Preparation of Pa/WC (polyaniline-waste carbon composites)}

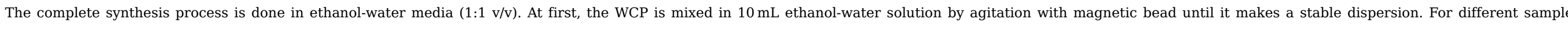

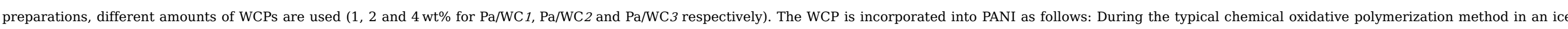

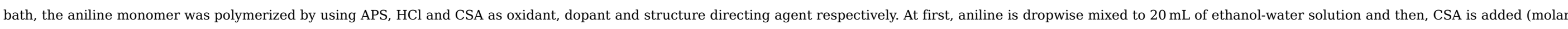

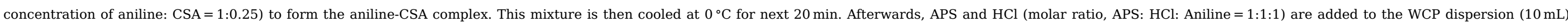

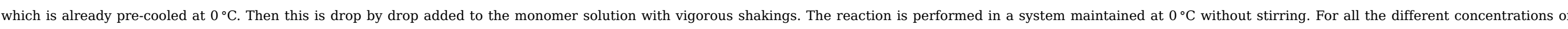

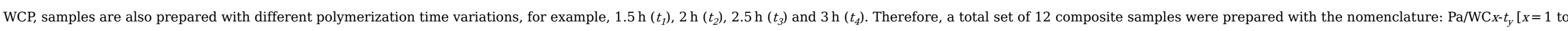

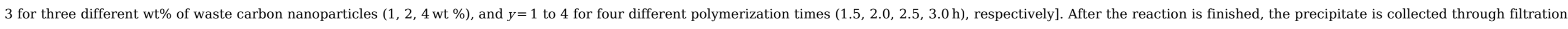

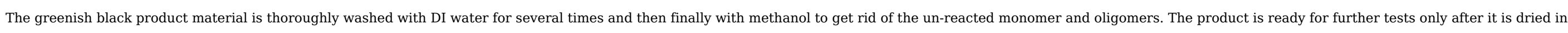
vacuum at $60^{\circ} \mathrm{C}$ for the next $24 \mathrm{~h}$.

\subsection{Preparation of Pa/WC electrochemical electrodes}

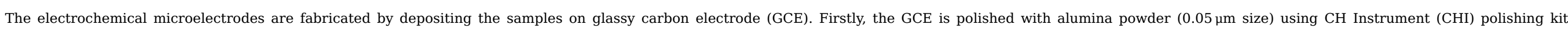

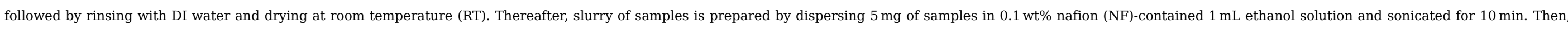

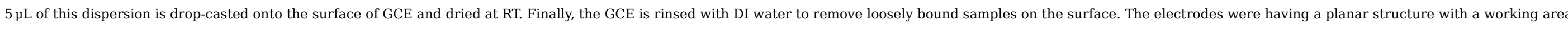

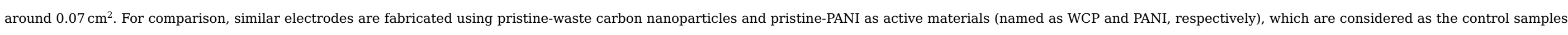

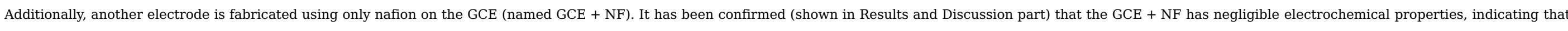
it has no contribution towards the electrochemical properties on the Pa/WC samples, i.e. all the electrochemical performances are purely being originated from the active materials.

\subsection{Characterization}

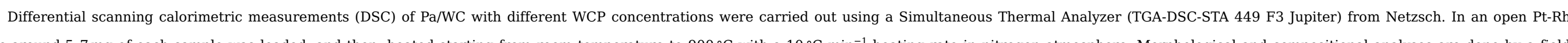

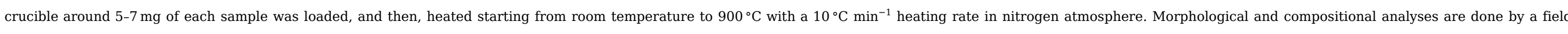

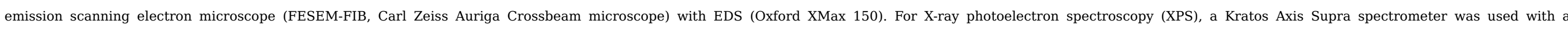

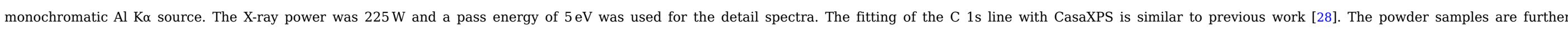

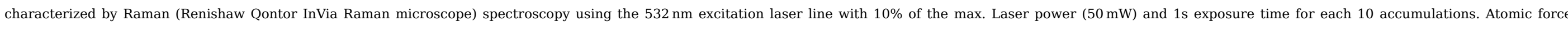

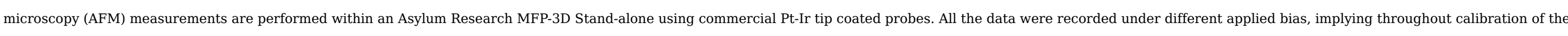

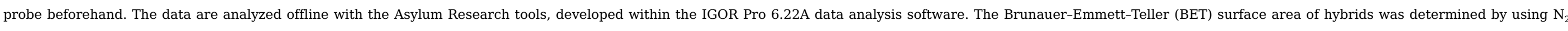

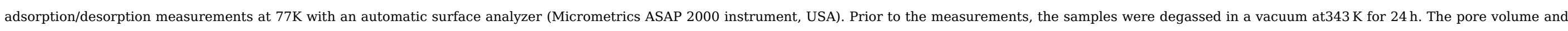




\subsection{Electrochemical characterization}

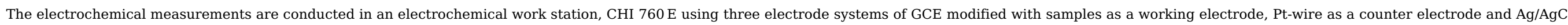
as a reference electrode. $1.0 \mathrm{M} \mathrm{KCl}$ solution is used as the electrolyte. The samples are subjected to:

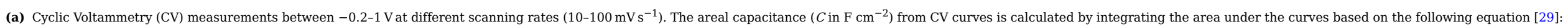

$$
C=\frac{1}{A \nu\left(V_{2}-V_{1}\right)} \int_{V_{1}}^{V_{2}} I(V) d V
$$

where $\nu\left(\mathrm{V} \mathrm{s}^{-1}\right)$ is the scan rate, $\left(V_{2}-V_{1}\right)$ is the potential window $(\mathrm{V}), I$ is the current $(\mathrm{A})$ and $A\left(\mathrm{~cm}^{2}\right)$ is the area of the working electrode $\left.(0.07 \mathrm{~cm})^{2}\right)$.

(b) Galvanometric charge-discharge (GCD) methods by varying current densities (15-100 $\left.\mathrm{A} \mathrm{cm}^{-2}\right)$. The areal capacitance from GCD curves is calculated according to the following equation [29]:

$$
C=\frac{I(\Delta t)}{(\Delta V) A}
$$

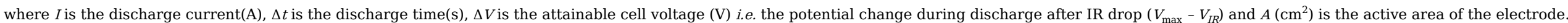

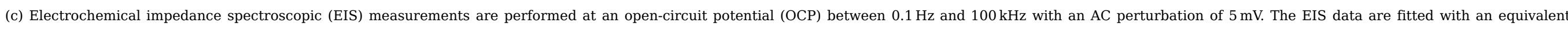

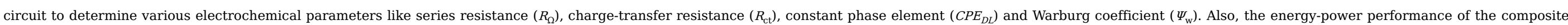
electrode is measured from the following equations (using GCD data) [30]:

$$
\begin{gathered}
\xi=\frac{C(\Delta V)^{2}}{2 \times 3600} \\
\Phi=\frac{E \times 3600}{\Delta t}
\end{gathered}
$$

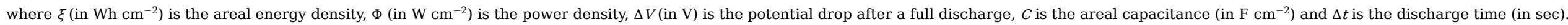

\section{Results and Discussion}

\subsection{Materials properties}

\subsubsection{Thermal behavior and chemical composition and surface analyses}

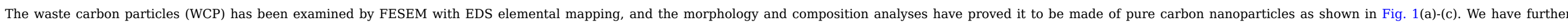

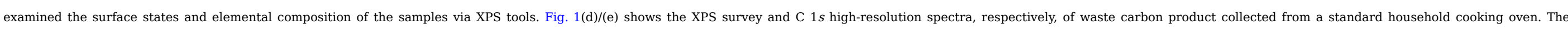

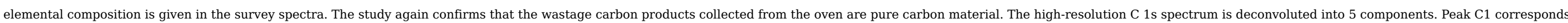
to $s p^{2}$ hybridized carbon (graphitic carbon), peak C2 is for $s p^{3}$ hybridized carbon, peaks C3 is due to the C in C-O bonds, peak C4 is the carbonyl C (C

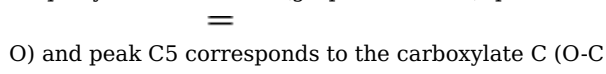

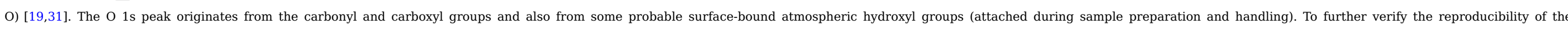

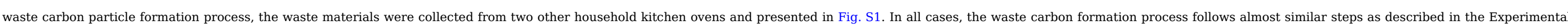

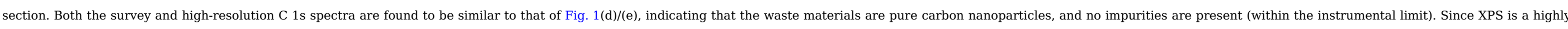

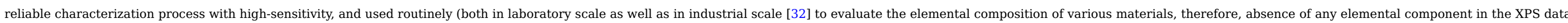
can authentically be considered to be either completely absent or too low to affect the physicochemical and/or electrochemical properties of the materials. 


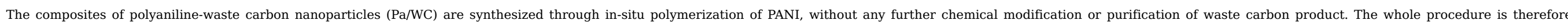

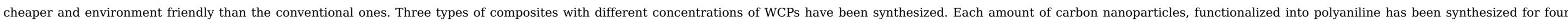

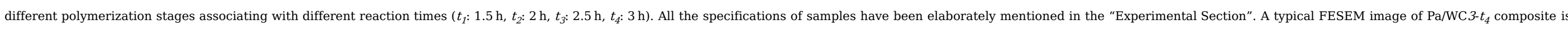

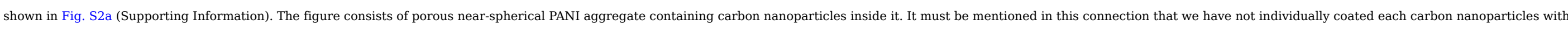

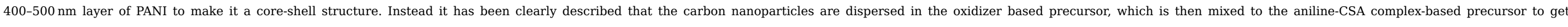

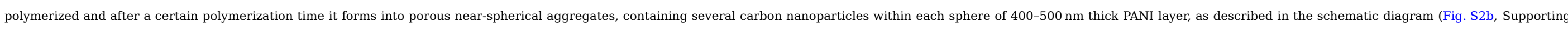

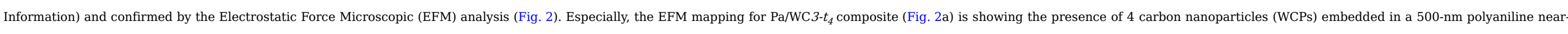

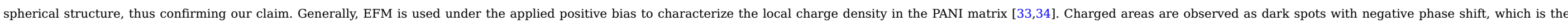

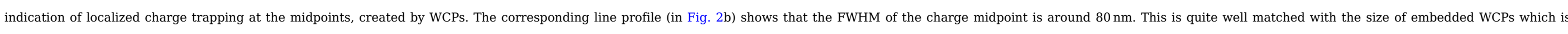

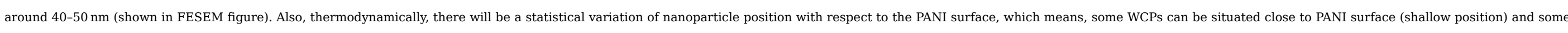

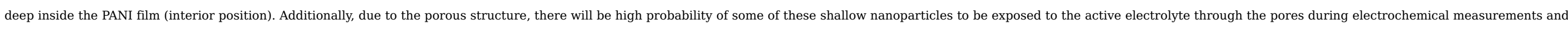
contribute to the overall supercapacitive performance of WCP-PANI composite (discussed in detail later).

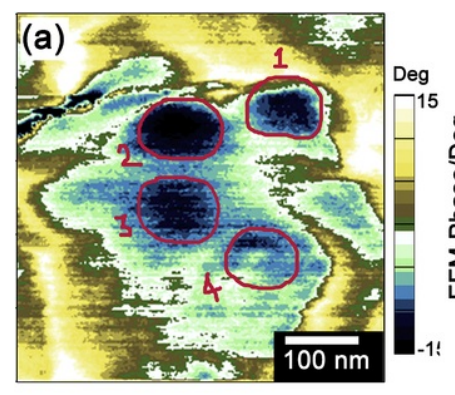

(b)

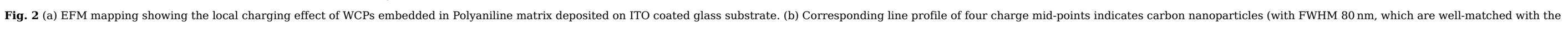
WCPs sizes found in FESEM). An offset is applied to all colour scales so that they are centered on the average value of the surface potential over the PANI matrix.

\section{alt-text: Fig. 2}

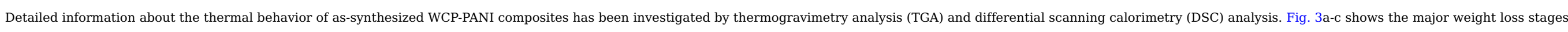

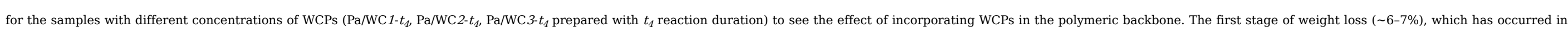

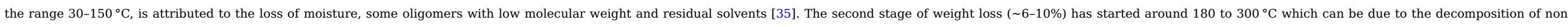

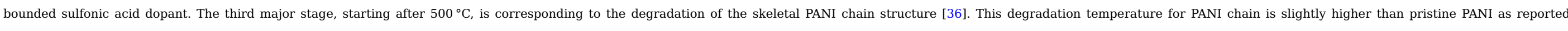

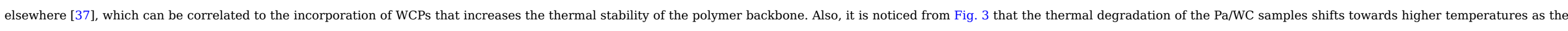
concentration of WCPs is increased. This signifies the interactions between macromolecular PANI chains and WCPs, revealing the formation of polyaniline-carbon interface with enhanced thermal stability. 

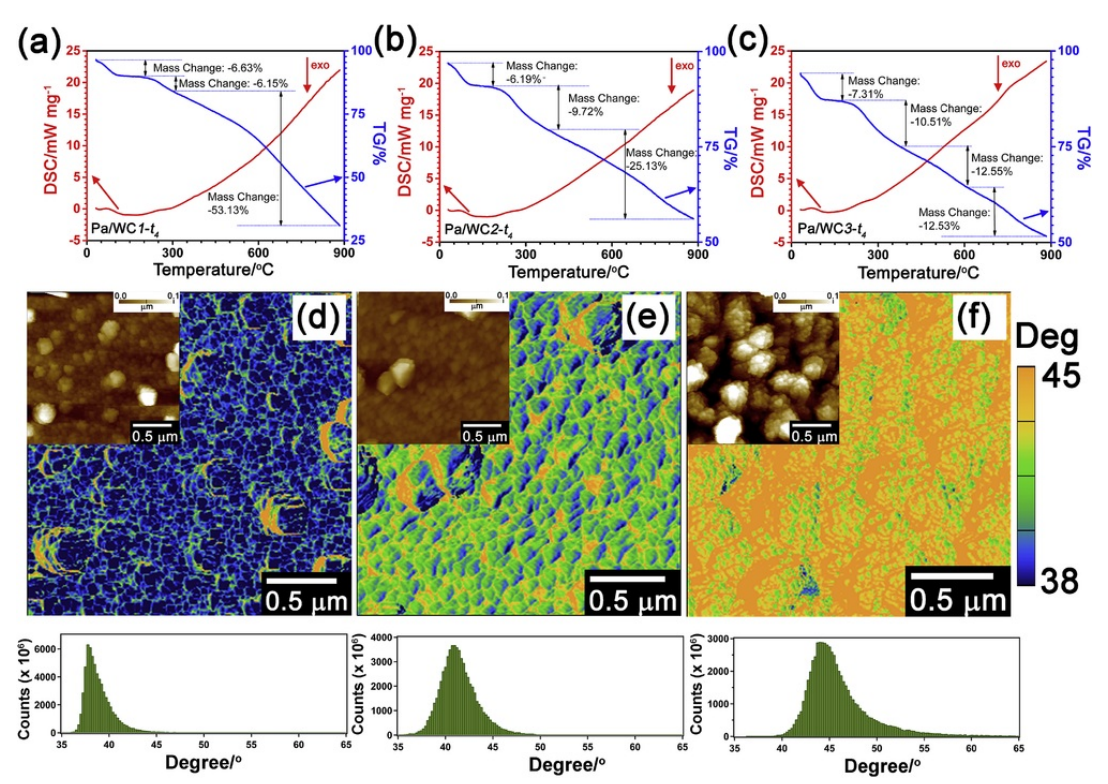

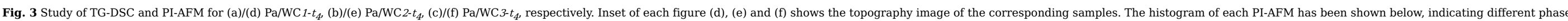
distribution according to percolation of WCP concentration into PANI.

\section{alt-text: Fig. 3}

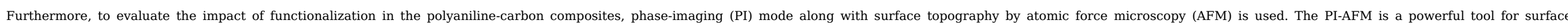

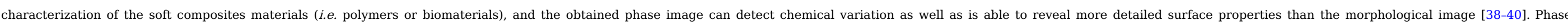

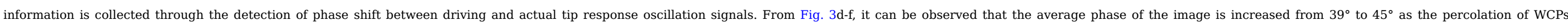

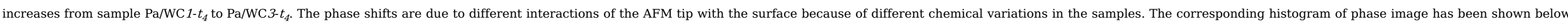

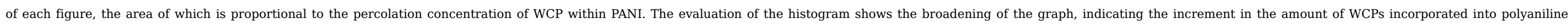

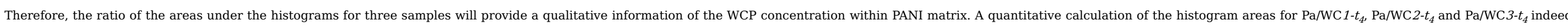

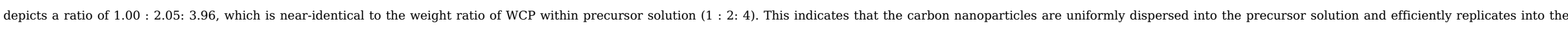
PANI-WCP composites. Also, similar trend is observed for all composites with different polymerization stages (e.g. Pa/WC1-3- $t_{1}-t_{3}$ ).

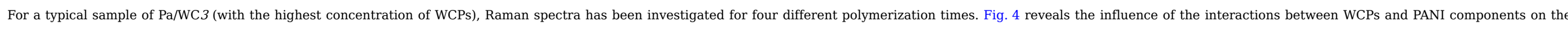

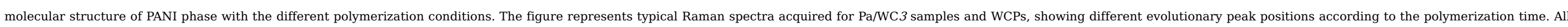

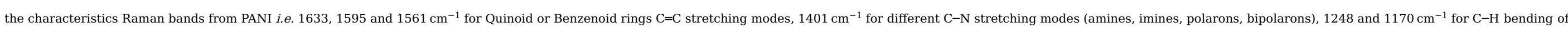

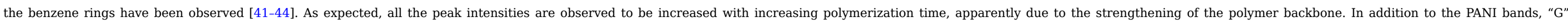

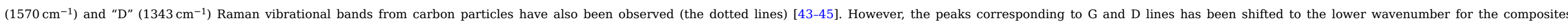

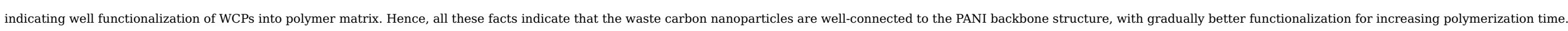




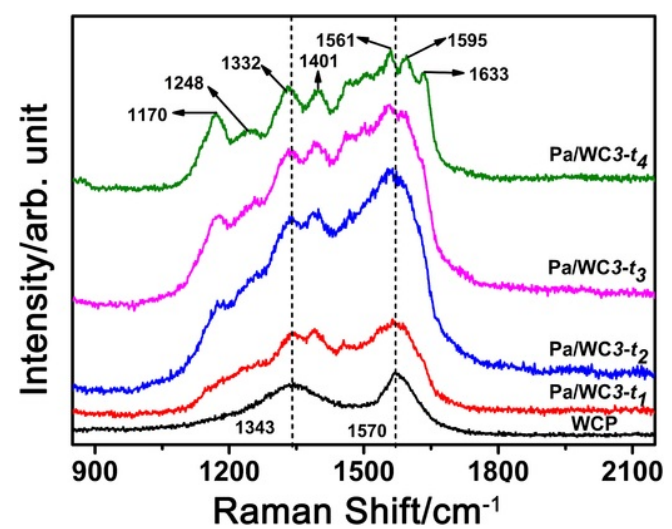

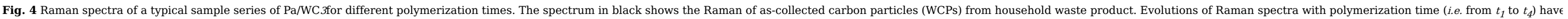
been clearly distinguished.

\section{alt-text: Fig. 4}

\subsubsection{Kelvin probe force microscopy}

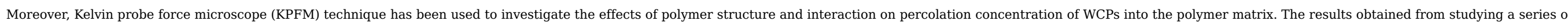

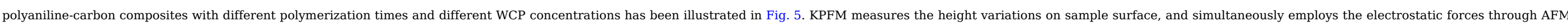

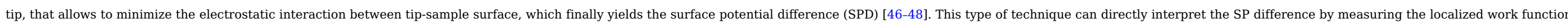

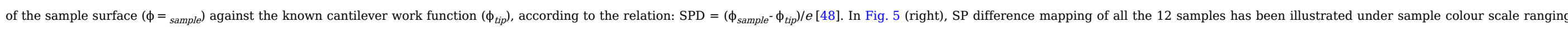

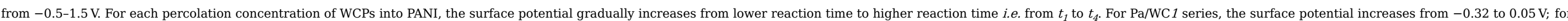

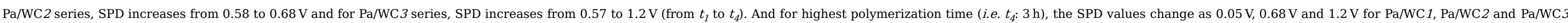

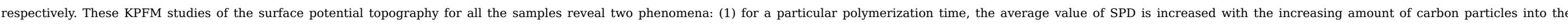

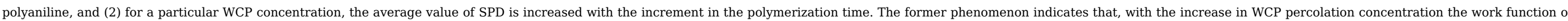

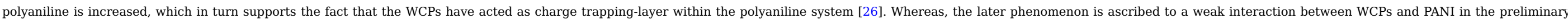
stage of reaction at lower polymerization time, and with the increase in time (from $t_{1}$ to $t_{4}$ ), WCPs (incorporated within PANI) lead to a strong п-п interaction.

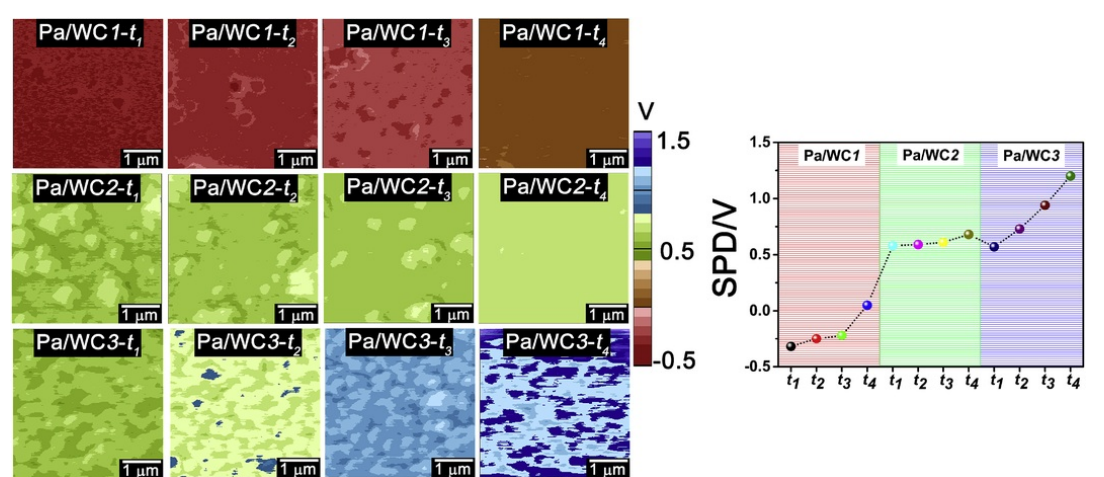

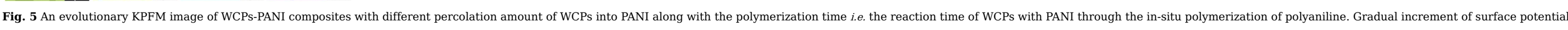

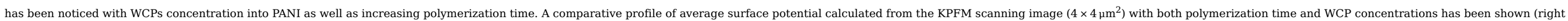




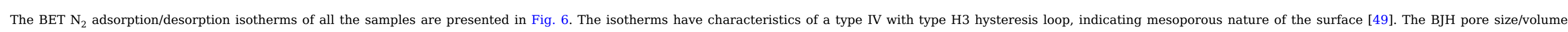

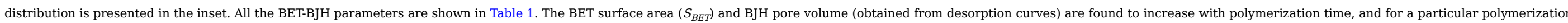

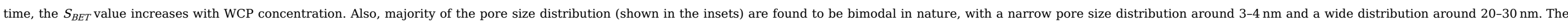

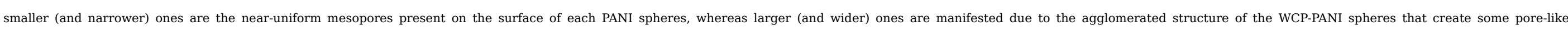
microstructure in-between the spheres (as shown in FESEM micrograph in Fig. S2a, Supporting Information).

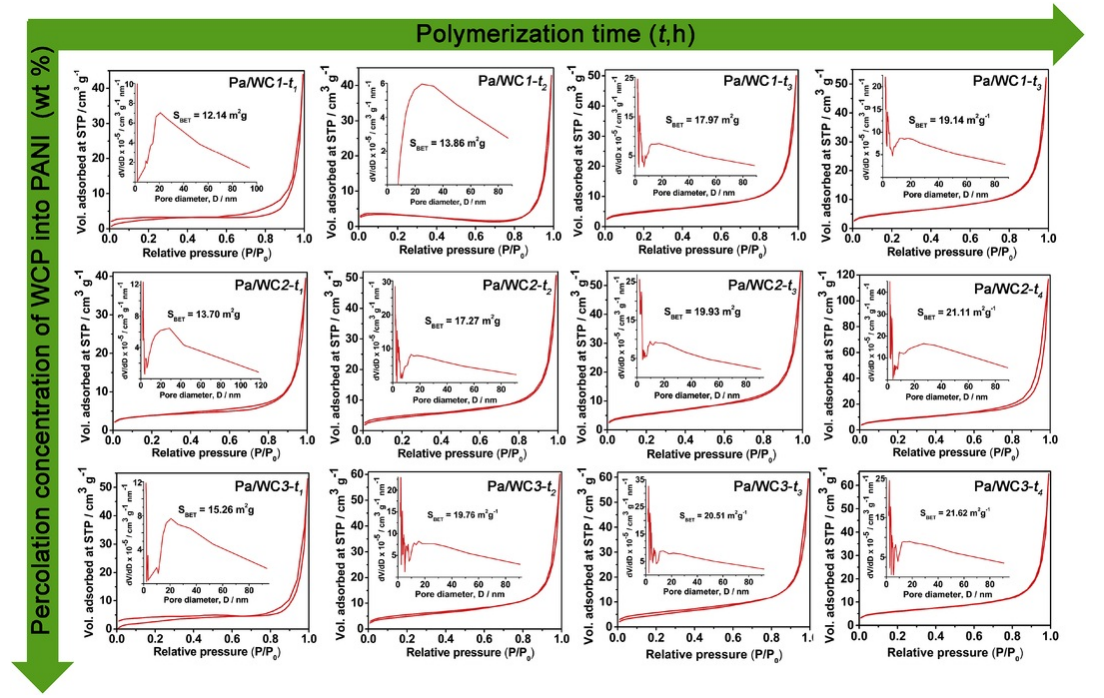

Fig. 6 BET N $\mathrm{N}_{2}$ adsorption/desorption isotherm curves for WCP-PANI composites. Insets: BJH pore size distribution. alt-text: Fig. 6

Table 1 BET-BJH and roughness data of WCP-PANI composites.

alt-text: Table 1

\begin{tabular}{|c|c|c|c|}
\hline Samples & BET surface area $/ \mathrm{m}^{2} \mathrm{~g}^{-1}$ & Avg. BJH pore volume $/ \mathrm{cm}^{3} \mathrm{~g}^{-1}$ & rms surface roughness/nm \\
\hline $\mathrm{Pa} / \mathrm{WC} 3-t_{1}$ & 15.26 & 0.081 & 35.1 \\
\hline $\mathrm{Pa} / \mathrm{WC} 3-t_{2}$ & 19.76 & 0.090 & 40.7 \\
\hline $\mathrm{Pa} / \mathrm{WC} 3-t_{3}$ & 20.51 & 0.091 & 58.7 \\
\hline $\mathrm{Pa} / \mathrm{WC} 3-t_{4}$ & 21.62 & 0.097 & 71.3 \\
\hline $\mathrm{Pa} / \mathrm{WC} 2-t_{1}$ & 13.70 & 0.068 & 25.6 \\
\hline $\mathrm{Pa} / \mathrm{WC} 2-t_{2}$ & 17.27 & 0.075 & 29.9 \\
\hline $\mathrm{Pa} / \mathrm{WC} 2-t_{3}$ & 19.93 & 0.083 & 34.6 \\
\hline $\mathrm{Pa} / \mathrm{WC} 2-t_{4}$ & 21.11 & 0.090 & 37.6 \\
\hline $\mathrm{Pa} / \mathrm{WC} 1-t_{1}$ & 12.14 & 0.065 & 14.9 \\
\hline
\end{tabular}




\begin{tabular}{|l|l|l|l|}
\hline Pa/WC $1-t_{2}$ & 13.86 & 0.066 & 17.5 \\
\hline Pa/WC $1-t_{3}$ & 17.97 & 0.076 & 25.7 \\
\hline Pa/WC $1-t_{4}$ & 19.14 & 0.078 & 29.8 \\
\hline
\end{tabular}

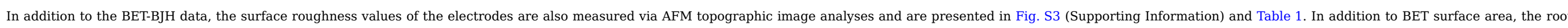

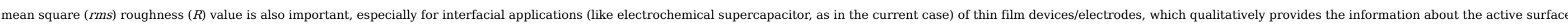

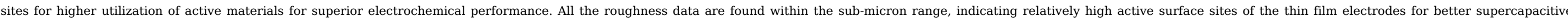

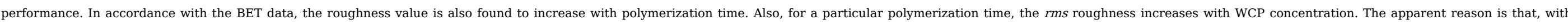

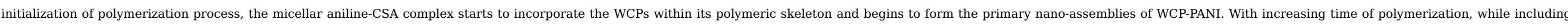

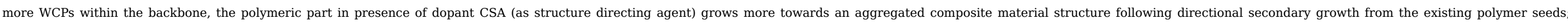
Henceforth, the roughness is found increasing with increasing polymerization time as well as with increasing WCP concentration.

\subsection{Electrochemical analyses}

\subsubsection{Cyclic voltammetry}

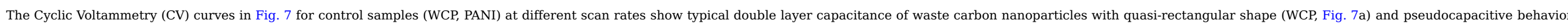

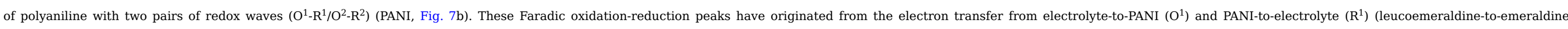

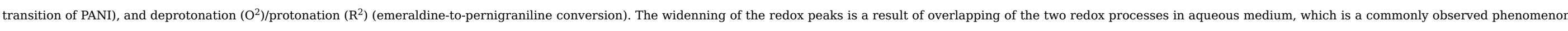
$[18,50,51]$.

(a)

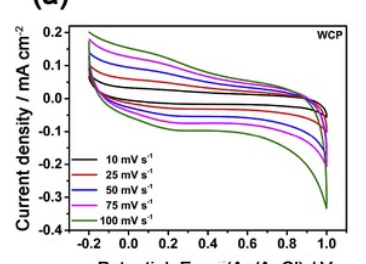

(d)

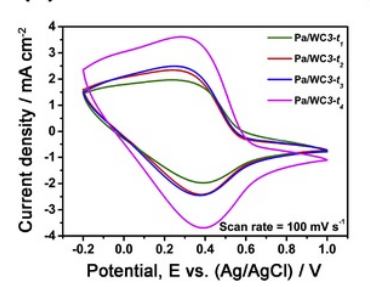

(b)

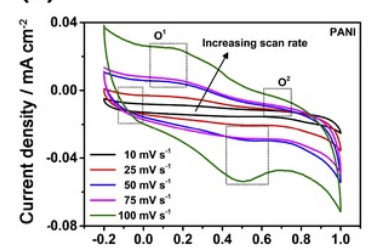

(e) (c)

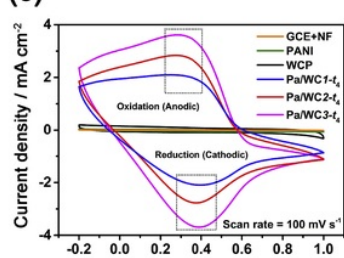

(f)

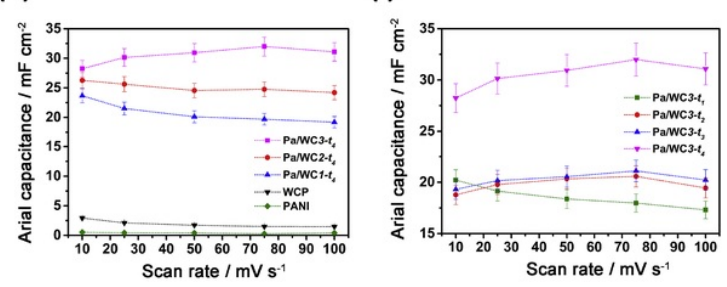

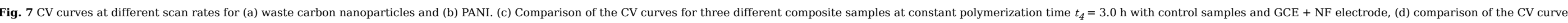

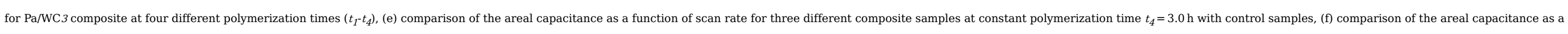
function of scan rate for Pa/WC 3 composite at four different polymerization times $\left(t_{1}-t_{4}\right)$.

alt-text: Fig. 7

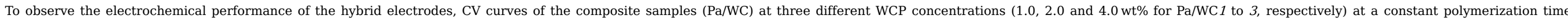

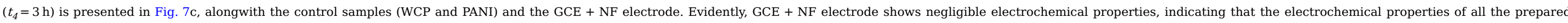




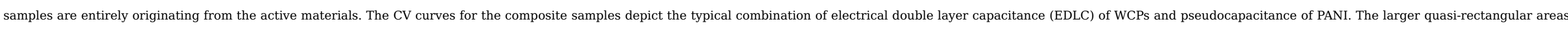

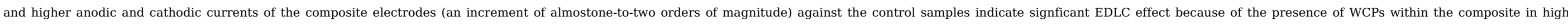

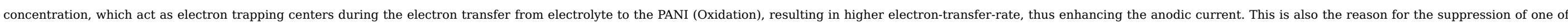

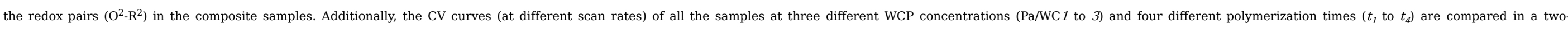

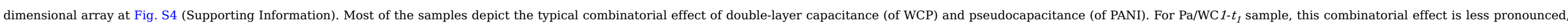

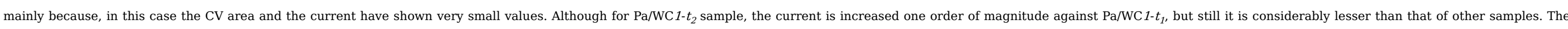

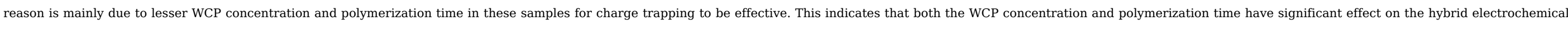

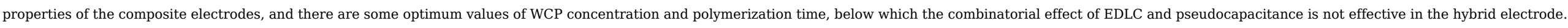

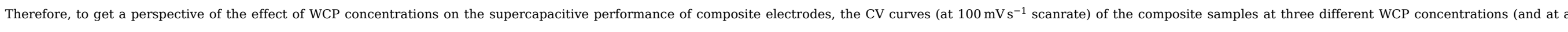

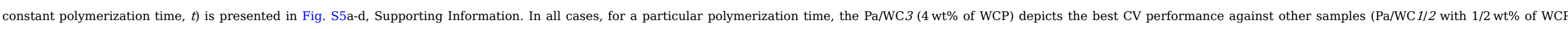

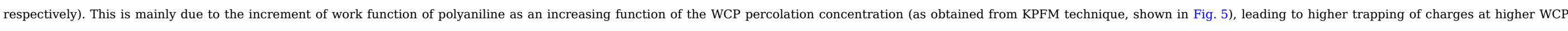

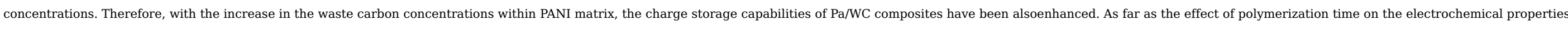

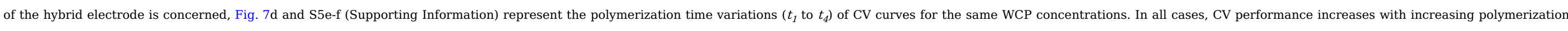

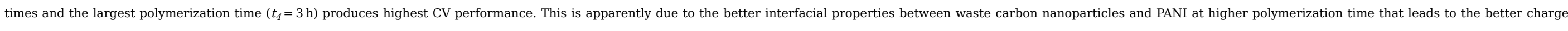
trapping and transport properties of the composites for superior electrochemical performance.

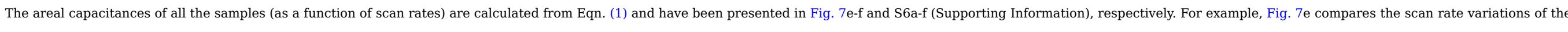

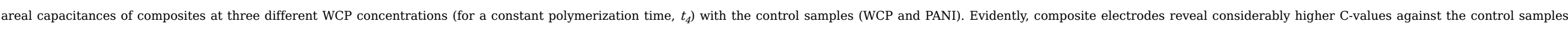

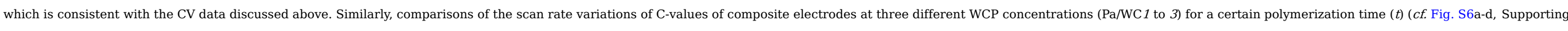

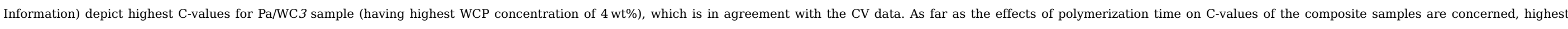

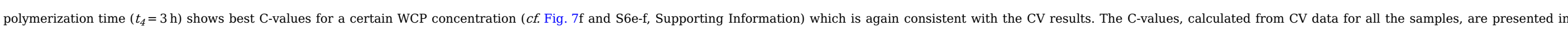

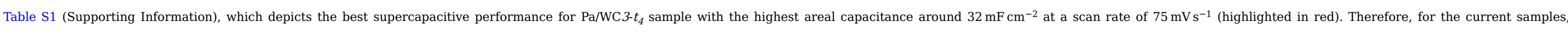
theoptimum $4 \mathrm{wt} \%$ carbon nanoparticle concentration within PANI matrix with an optimum polymerization time of $3 \mathrm{~h}$ produces the best supercapacitive performance of the Pa/WC hybrid electrodes.

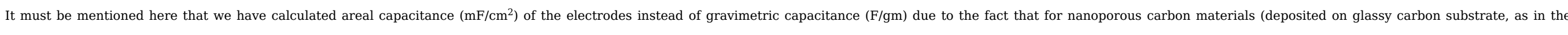

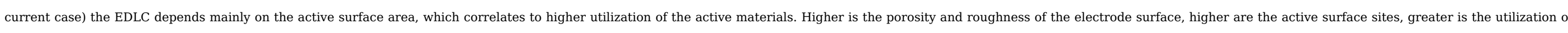

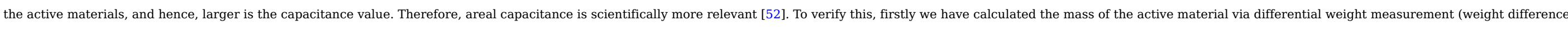

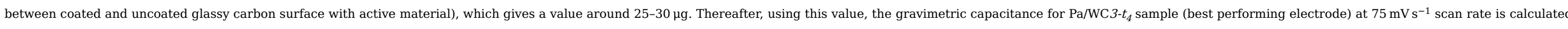

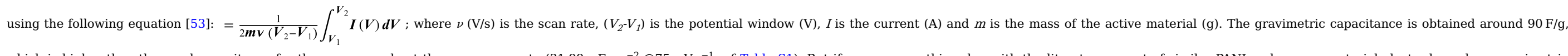

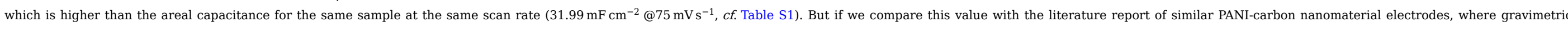

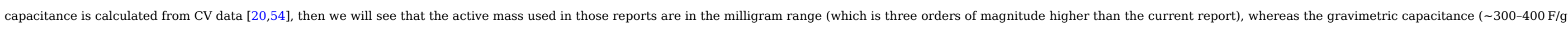

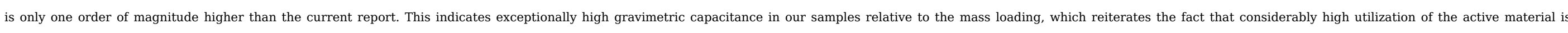

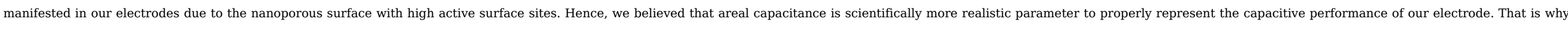
we have used areal capacitance throughout the manuscript.

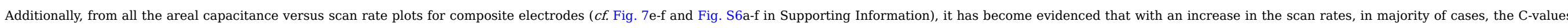

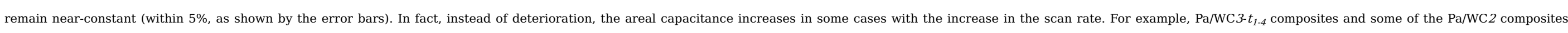

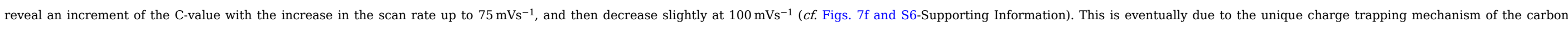
nanoparticles within PANI (explained below), which indicates excellent rate capability of the composite electrodes [55]. 


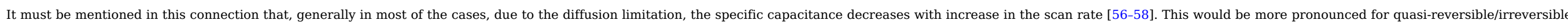

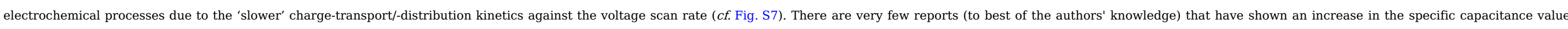

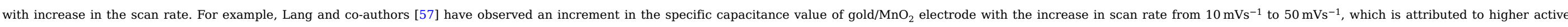

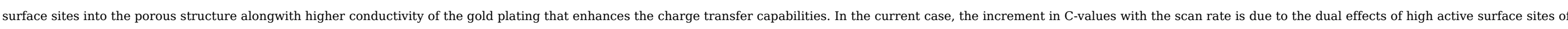

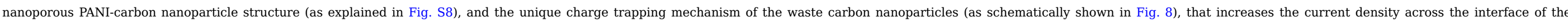

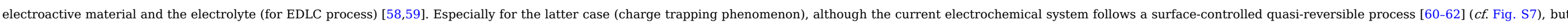

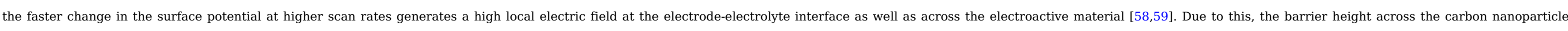

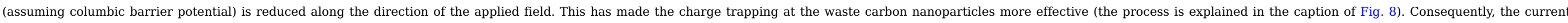

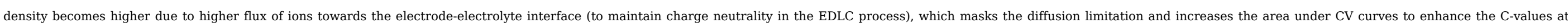

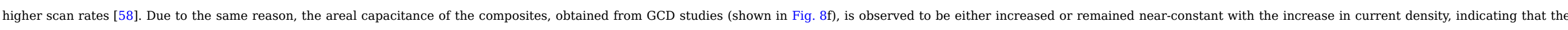
distinct charge trapping process of carbon nanoparticles within PANI increases the discharging time considerably to enhance the C-values at higher current densities.

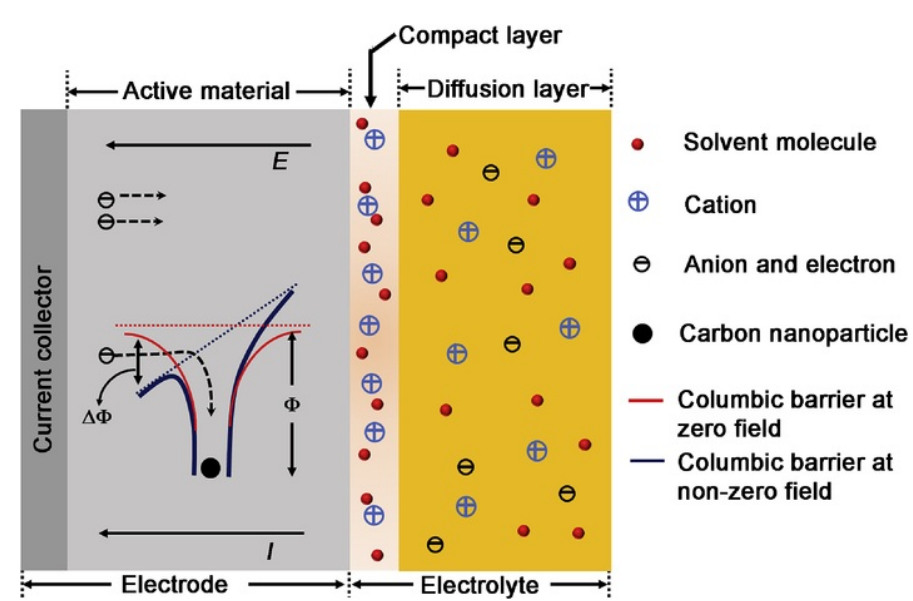

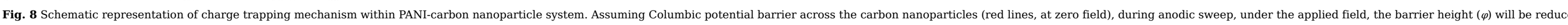

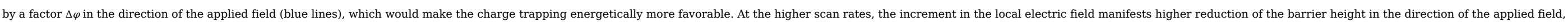

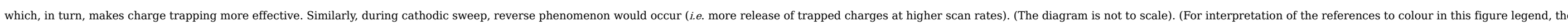
reader is referred to the Web version of this article.)

\section{alt-text: Fig. 8}

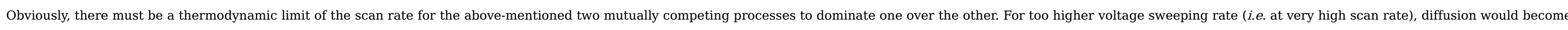

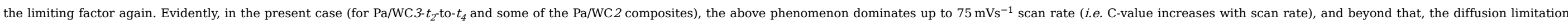
starts dominating (i.e. C-value decreases slightly at $100 \mathrm{mVs}^{-1}$ scan rate), mainly due to considerably quicker voltage sweeping rate as discussed above.

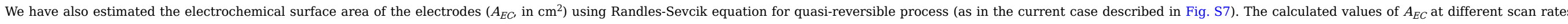

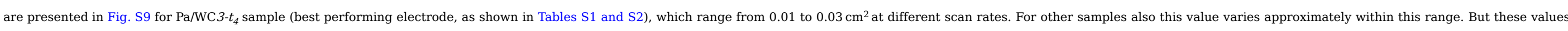

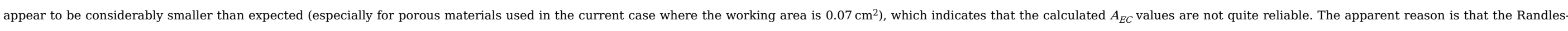

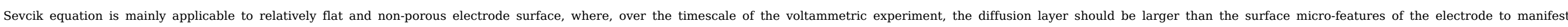

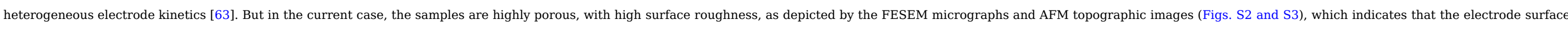
micro-features are comparable and/or lesser than the diffusion length, and hence go undetected, leading to underestimated values of electrochemical surface area. 


\subsubsection{Galvanostatic charge-discharge curves}

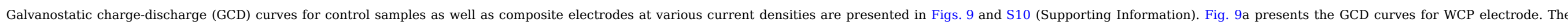

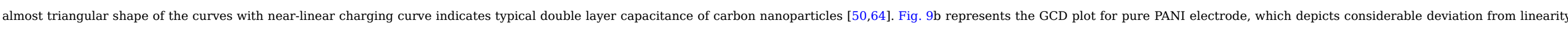

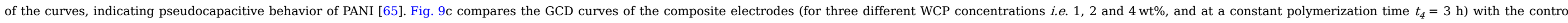

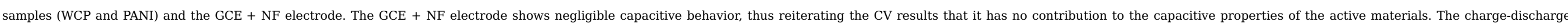

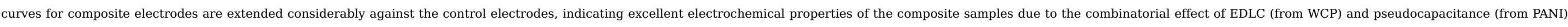

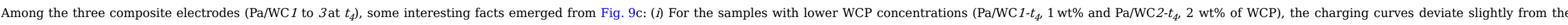

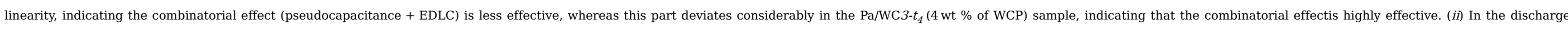

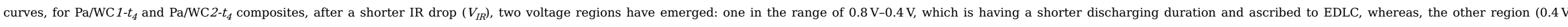

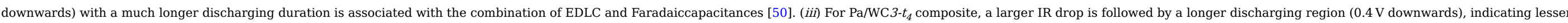

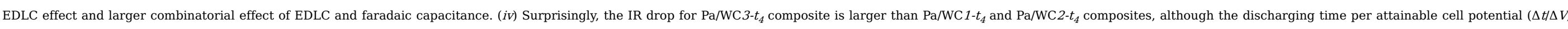

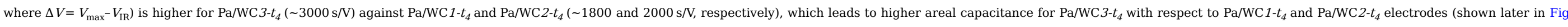

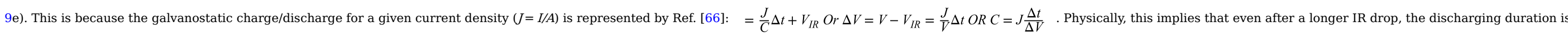

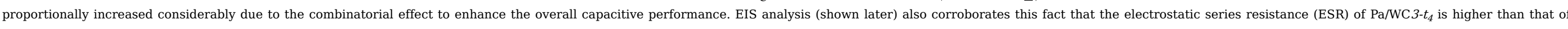

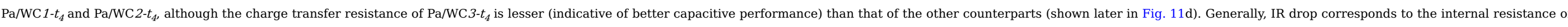

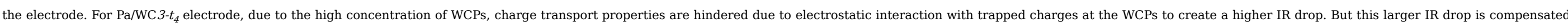

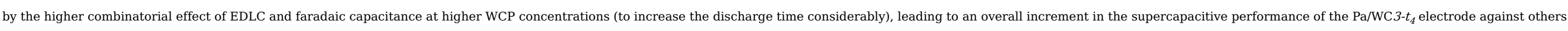

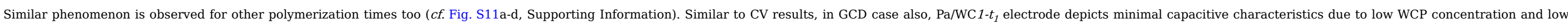
polymerization time.

(a)

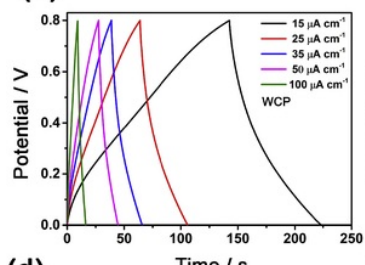

(d)

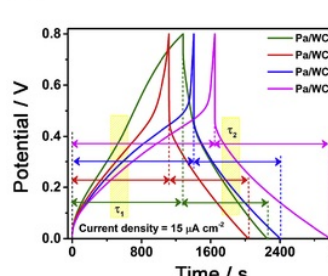

Time /s

(b)

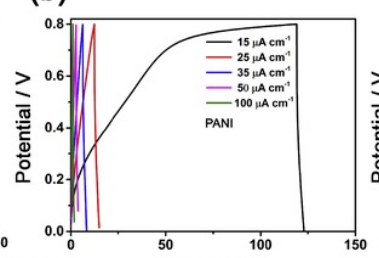

(e)

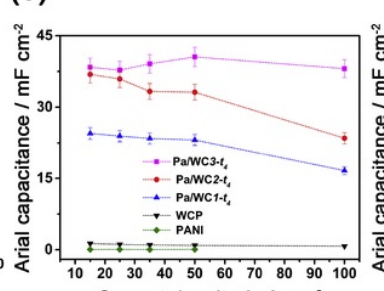

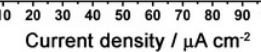

(c)

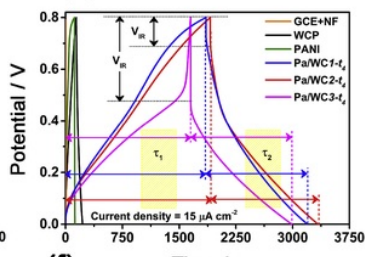

(f)

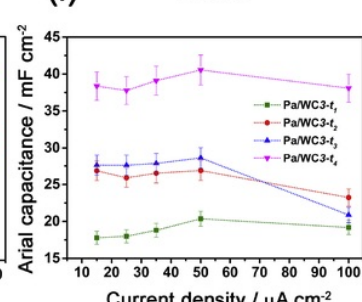

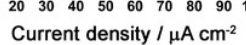

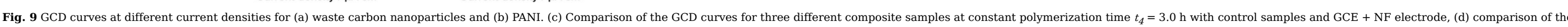

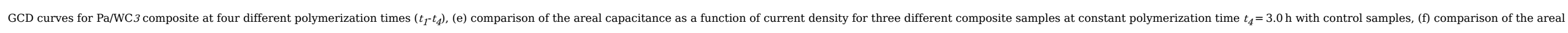
capacitance as a function of current density for Pa/WC 3 composite at four different polymerization times $\left(t_{1}-t_{4}\right)$. 


\section{(a)}

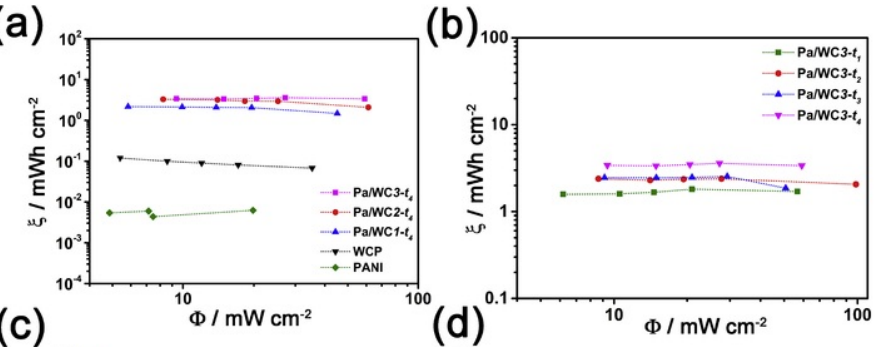

(c)

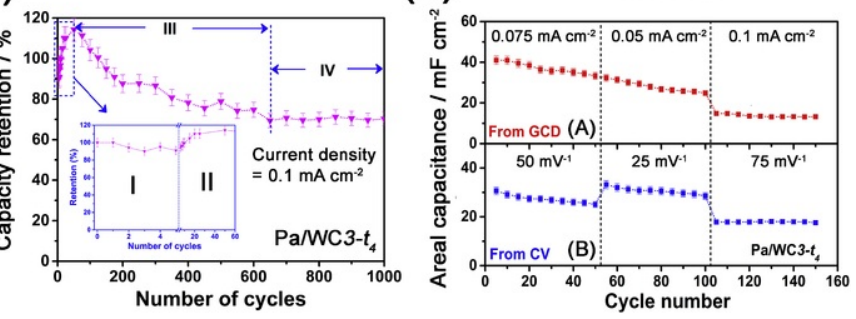

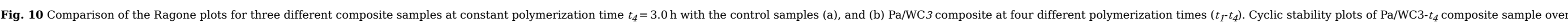
1000 cycles (c), and (d) at progressively varied scan rates (A)/current densities (B). Inset of (c) is the cyclic stability for first 50 cycles. (d) Shows the cyclic performance at progressively varying scan rates (A) and current densities (B), respectively. alt-text: Fig. 10
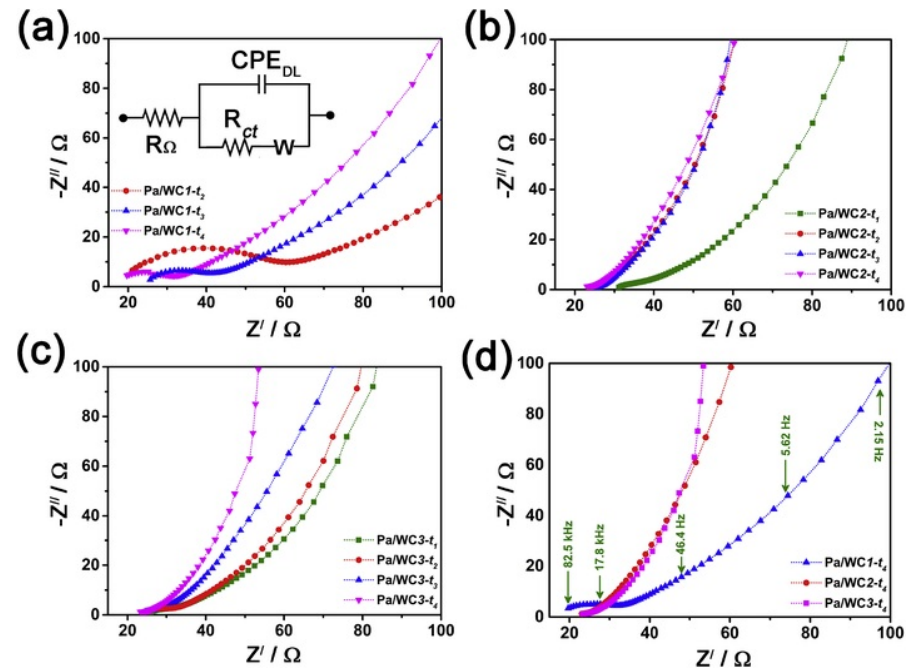

Fig. 11 Nyquist plots for composite electrodes, Pa/WC1- $t_{2}$ to $t_{4}$ (a), Pa/WC2-t $t_{1}$ to $t_{4}$ (b), Pa/WC $3-t_{1}$ to $t_{4}$, and (c) comparison of three composites Pa/WC1 to 3 at $t_{4}$ (d). Inset of (a) represents the equivalent circuit. alt-text: Fig. 11

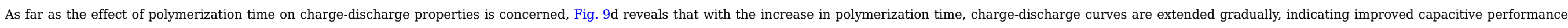

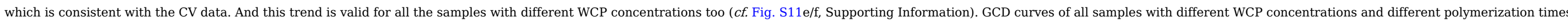

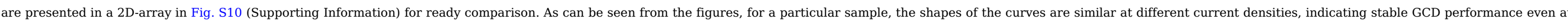

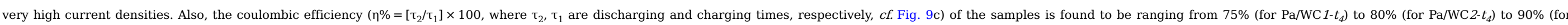

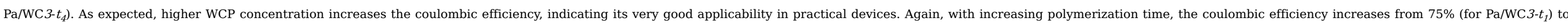




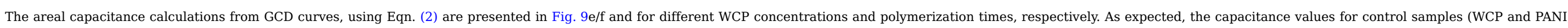

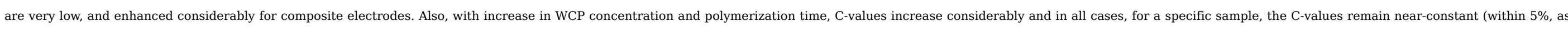

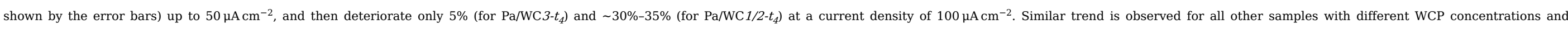

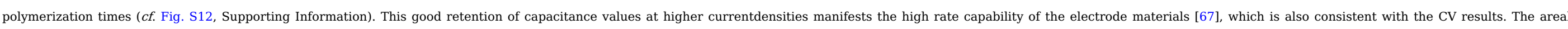

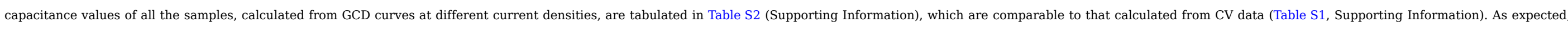
Pa/WC3- $t_{4}$ composite (having highest WCP concentration of $4 \mathrm{wt} \%$ and longest polymerization time of $3 \mathrm{~h}$ ) reveals best capacitance values (highlighted with red) against all other samples, which is consistent with the CV data.

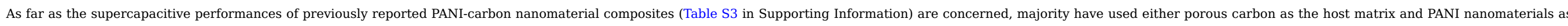

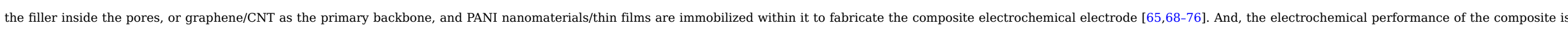

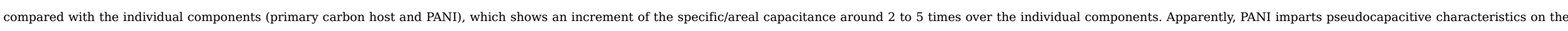

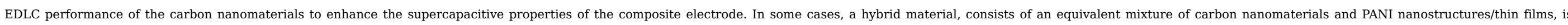

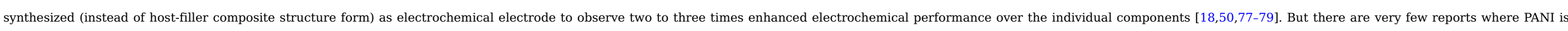

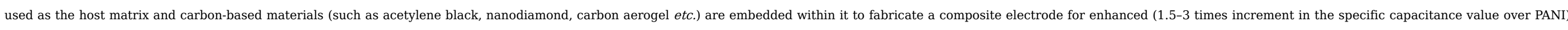

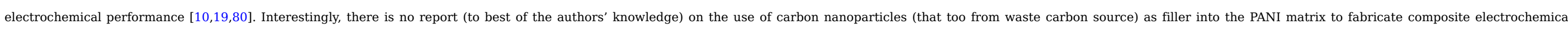

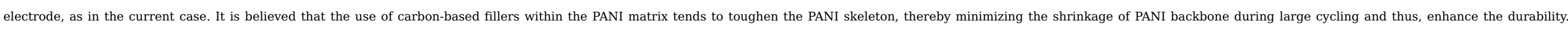

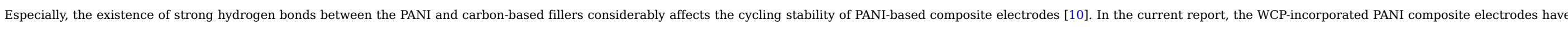

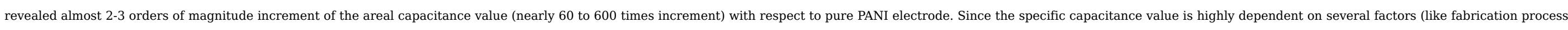

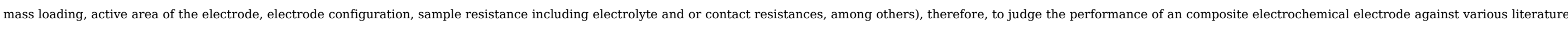

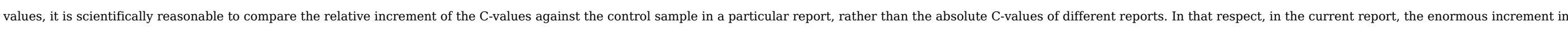
the areal capacitance of the Pa/WC composite against pure PANI electrode clearly highlights the novelty of the current material and the method, and hence, warrants considerable attention.

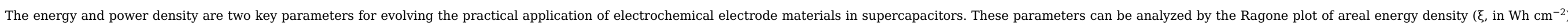

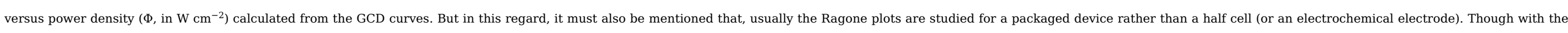

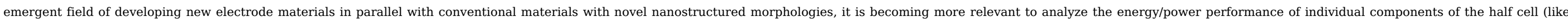

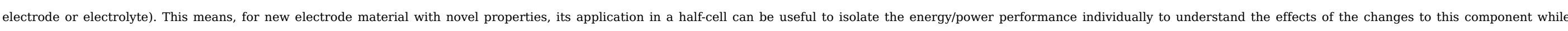

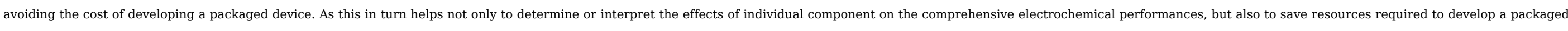

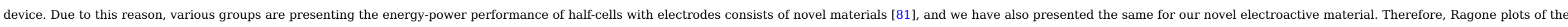

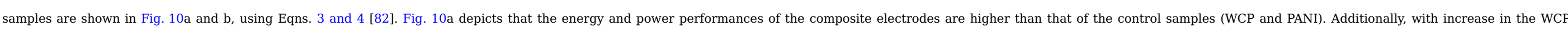

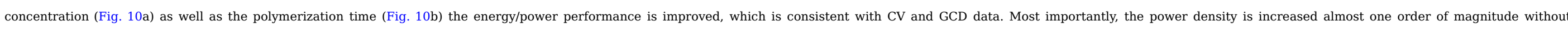

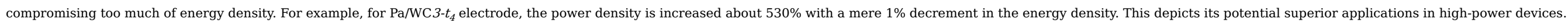

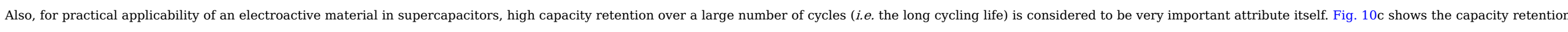

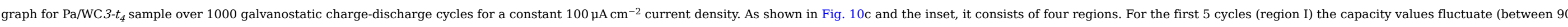

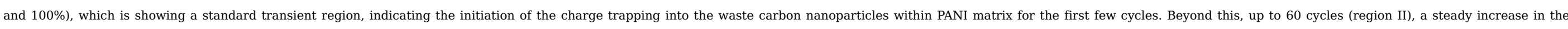

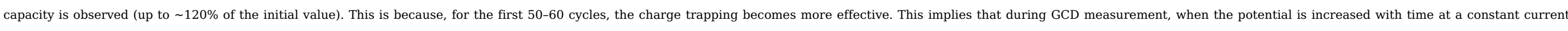

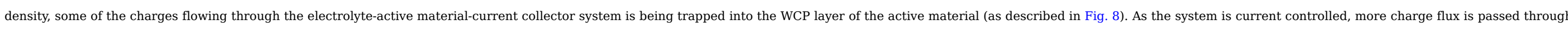

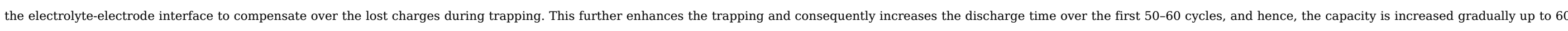

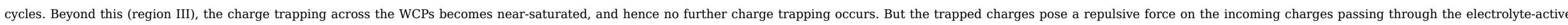




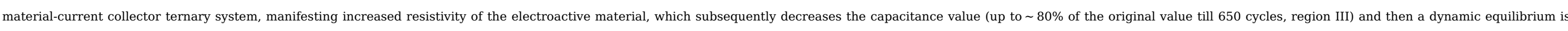

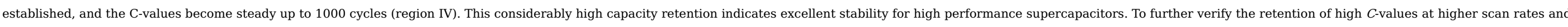

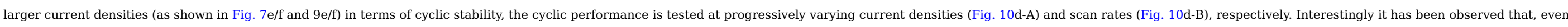

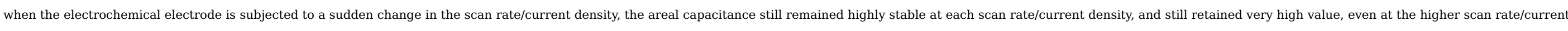
density. These results indicate that the Pa/WC composites meet the two important requirements of long cycling lifetime and good rate capability for potential applications in practical energy storage devices [55].

\subsubsection{Electrochemical impedance spectroscopic measurements}

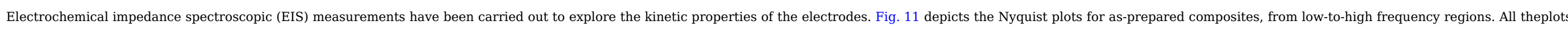

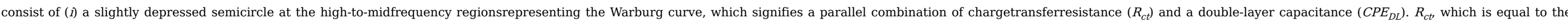

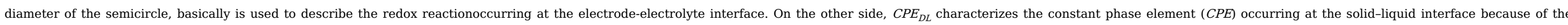

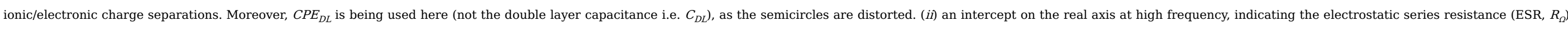

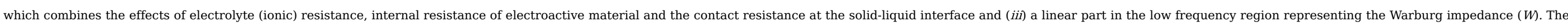

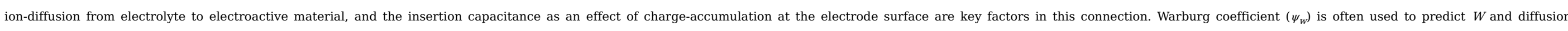

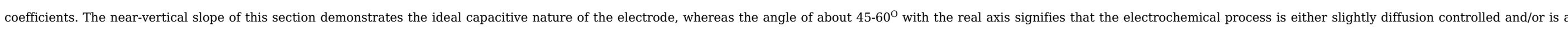

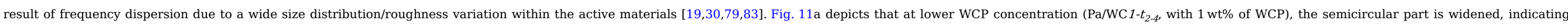

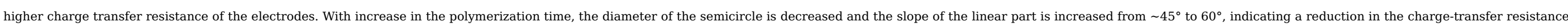

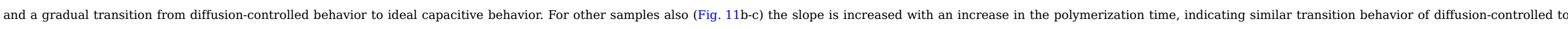

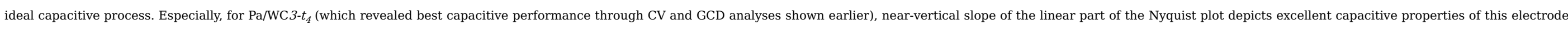

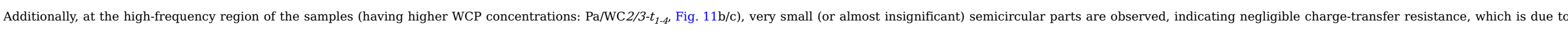

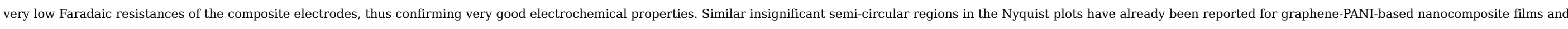

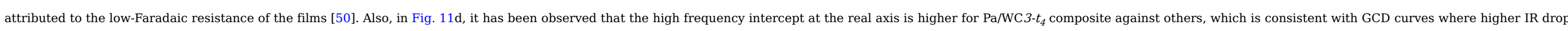

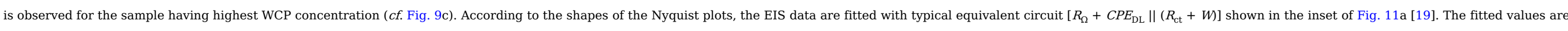

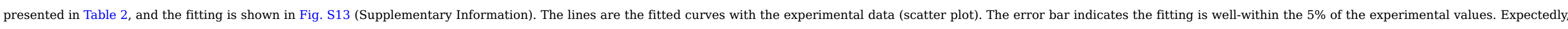

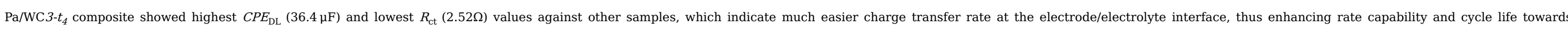

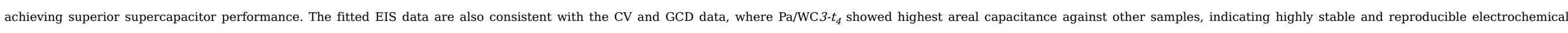
properties of the samples.

Table 2 Fitted values of EIS data from the Nyquist plots.

alt-text: Table 2

\begin{tabular}{|c|c|c|c|}
\hline EIS parameters & $\mathrm{Pa} / \mathrm{WC} 1-t_{4}$ & $\mathrm{~Pa} / \mathrm{WC} 2-t_{4}$ & $\mathrm{~Pa} / \mathrm{WC} 3-t_{4}$ \\
\hline $\mathrm{R} \Omega / \Omega$ & 18.4 & 20.63 & 23.41 \\
\hline $\mathrm{CPE}_{\mathrm{DL}} / \mu \mathrm{F}$ & 0.367 & 1.22 & 36.4 \\
\hline $\mathrm{R}_{c l} / \Omega$ & 19.19 & 3.12 & 2.52 \\
\hline$\Psi_{\mathrm{w}} / \Omega \mathrm{s}^{-1 / 2}$ & 242.0 & 169.1 & 119.1 \\
\hline
\end{tabular}

\section{Conclusions}

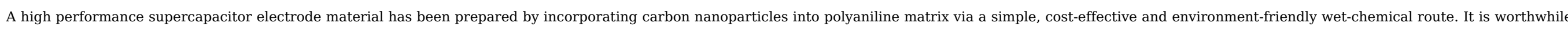




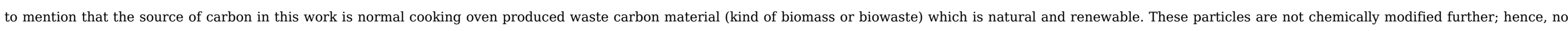

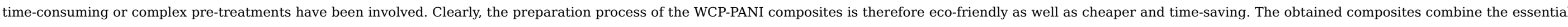

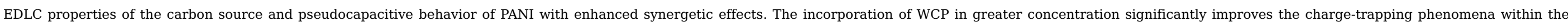

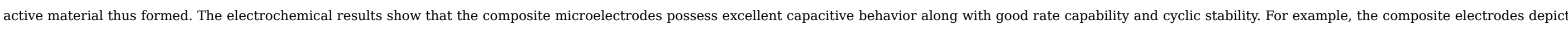

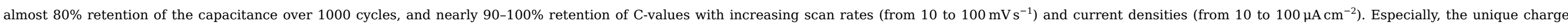

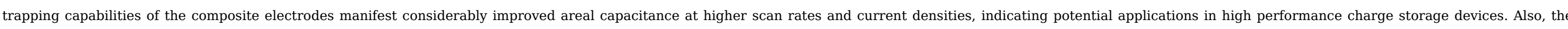

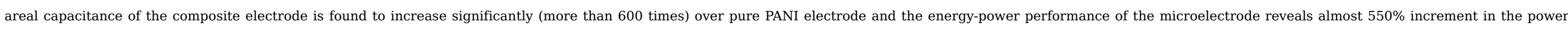

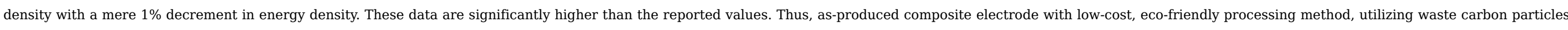
as one of its major components, can contribute towards the development of promising and highly efficient supercapacitors using green nanotechnology for energy storage systems.

\section{Acknowledgements}

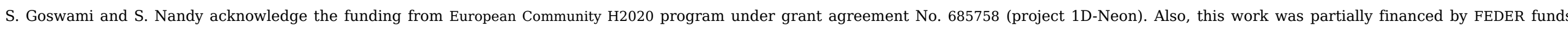

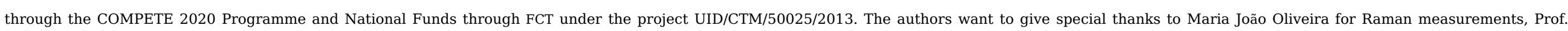
Daniela Nunes for FESEM measurements and Dr. Jonas Deuermeier for XPS measurement.

\section{Appendix A. Supplementary data}

Supplementary data to this article can be found online at https://doi.org/10.1016/j.electacta.2019.05.133.

\section{References}

[1] M.F. El-Kady, Y. Shao and R.B. Kaner, Graphene for batteries, supercapacitors and beyond, Nat. Rev. Mater. 1 (14pp), $2016,16033$.

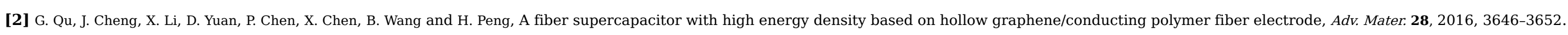

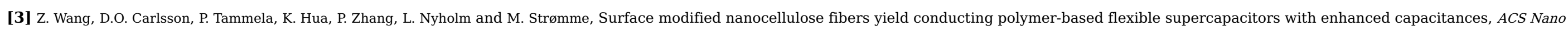
9, 2015, 7563-7571.

[4] A. González, E. Goikolea, J.A. Barrena and R. Mysyk, Review on supercapacitors: technologies and materials, Renew. Sustain. Energy Rev. 58, 2016, 1189-1206.

[5] B.E. Conway, Electrochemical Supercapacitors: Scientific Fundamentals and Technological Applications, 1999, Kluwer; New York.

[6] A. Nishino, Capacitors: operating principles, current market and technical trends, J. Power Sources 60, 1996, 137-147.

[7] J.R. Miller and P. Simon, Electrochemical capacitors for energy management, Science 321, 2008, 651-652.

[8] P. Simon and Y. Gogotsi, Materials for electrochemical capacitors, Nat. Mater. 7, 2008, 845-854.

[9] M. Mastragostino, F. Soavi and C. Arbizzani, Electrochemical supercapacitors, In: W. van Schalkwijk and B. Scrosati, (Eds.), Advances in Lithium-Ion Batteries, 2002 , Springer; Boston, MA, 481-505.

[10] I. Kovalenko, D.G. Bucknall and G. Yushin, Detonation nanodiamond and onion-like-carbon-embedded polyaniline for supercapacitors, Adv. Funct. Mater. 20, 2010, 3979-3986.

[11] C. Falco, M. Sevilla, R.J. White, R. Rothe and M.M. Titirici, Renewable nitrogen-doped hydrothermal carbons derived from microalgae, Chem. Sus. Chem. 5, 2012, 1834-1840.

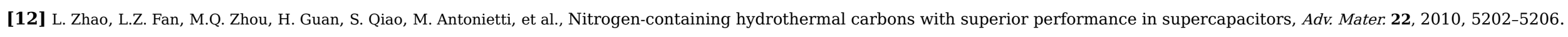

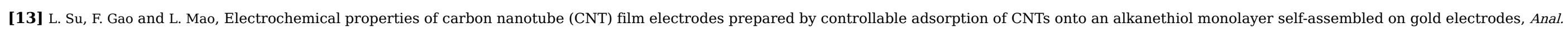
Chem. 78, 2006, 2651-2657. 


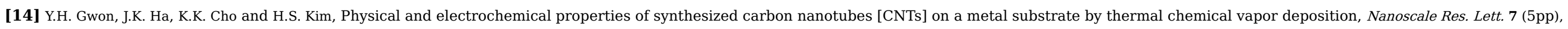
$2012,61$.

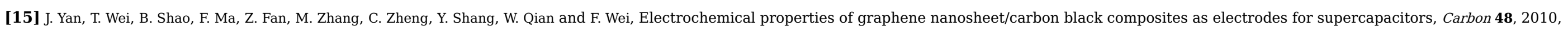
$1731-1737$.

[16] G.A. Snook, P. Kao and A.S. Best, Conducting-polymer-based supercapacitor devices and electrodes, J. Power Sources 196, 2011 , 1-12.

[17] A. Eftekhari, L. Li and Y. Yang, Polyaniline supercapacitors, J. Power Sources 347, 2017, 86-107.

[18] Z. Lei, Z. Chen and X.S. Zhao, Growth of polyaniline on hollow carbon spheres for enhancing electrocapacitance, J. Phys. Chem. C114, 2010, 19867-19874.

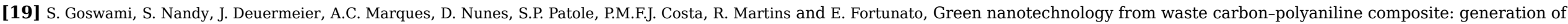
wavelength-independent multiband photoluminescence for sensitive ion detection, Adv. Sust. Sys. 2 (11pp), 2018, 1700137.

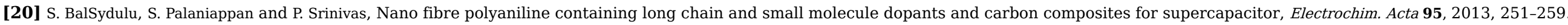

[21] C. Zhan, X. Yu, Q. Liang, W. Liu, Y. Wang, R. Lv, Z.-H. Huang and F. Kang, Flour food waste derived activated carbon for high-performance supercapacitors, RSC Adv. 6, 2016, 89391-89396.

[22] P. Cheng, T. Li, H. Yu, L. Zhi, Z. Liu and Z. Lei, Biomass-derived carbon fiber aerogel as a binder-free electrode for high-rate supercapacitors, J. Phys. Chem. C120, 2016, 2079-2086.

[23] W. Qian, F. Sun, Y. Xu, L. Qiu, C. Liu, S. Wang and F. Yan, Human hair-derived carbon flakes for electrochemical supercapacitors, Energy Environ. Sci. 7, 2014 , 379-386.

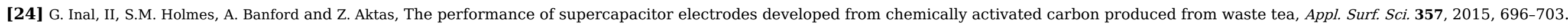

[25] X. Gu, Y. Wang, C. Lai, J. Qiu, S. Li, Y. Hou, W. Martens, N. Mahmood and S. Zhang, Microporous bamboo biochar for lithium-sulfur batteries, Nano Res. 8, $2015,129-139$.

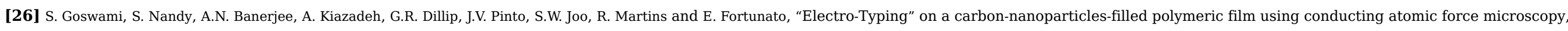
Adv. Mater. 29 (9pp), 2017, 1703079.

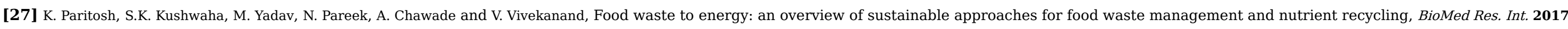
2017, 19, Article ID 2370927.

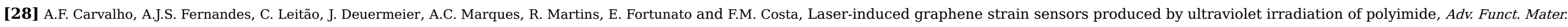
28, 2018, 1805271

[29] M. Zhen, S. Guo, G. Gao, Z. Zhou and L. Liu, $\mathrm{TiO}_{2}$-B nanorods on reduced graphene oxide as anode materials for Li ion batteries, Chem. Commun. 51, 2015, 507-510.

[30] M. Ates, Review study of electrochemical impedance spectroscopy and equivalent electrical circuits of conducting polymers on carbon surfaces, Prog. Org. Coating 71, 2011, 1-10.

[31] S.Z. Mortazavi, P. Parvin, A. Reyhani, S. Mirershadi and R.S. Bonabi, Generation of various carbon nanostructures in water using IR/UV laser ablation, Phys. D: Appl. Phys. 46, 2013 , 165303.

[32] A.J. Roberts and C.E. Moffitt, Trends in XPS instrumentation for industrial surface analysis and materials characterisation, J. Electron. Spectrosc. Relat. Phenom. 231, 2019, 68-74.

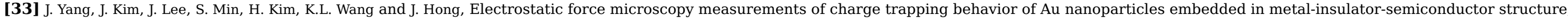
Ultramicroscopy 108, 2008, 1215-1219.

[34] P. Girard, Electrostatic force microscopy: principles and some applications to semiconductors, Nanotechnology 12, 2001, 485-490.

[35] A. Lodha, S.M. Kilbey, P.C. Ramamurthy and R.V. Gregory, Effect of annealing on electrical conductivity and morphology of polyaniline films, J. Appl. Polym. Sci. 82, 2001, 3602-3610.

[36] W.A.K. Mahmood and M.H. Azarian, Sol-gel synthesis of polyaniline/zirconia composite conducting materials, J. Polym. Res. 23 (8pp), 2016 , 88. 
[37] G. Gheno, N.R.S. Basso and R. Hubler, Polyaniline/Graphite nanocomposites: synthesis and characterization, Macromol. Symp. 299/300, 2011, 74-80.

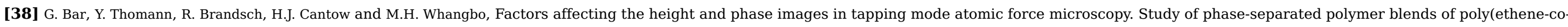
styrene) and poly(2,6-dimethyl-1,4-phenylene oxide), Langmuir 13, 1997, 3807-3812.

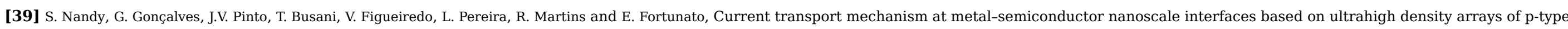
NiO nano-pillars, Nanoscale 5, 2013, 11699-11709.

[40] A. Leon, B.J. Rodier, Q. Luo, C.M. Hemmingsen, P. Wei, K. Abbasi, R. Advincula and E.B. Pentzer, Distinct chemical and physical properties of janus nanosheets, ACS Nano 11, 2017, 7485-7493.

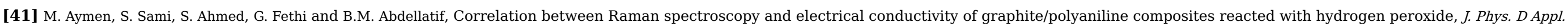
Phys. 46 (6pp), 2013, 335103.

[42] G.M. do Nascimento and M.L.A. Temperini, Studies on the resonance Raman spectra of polyaniline obtained with near-IR excitation, J. Raman Spectrosc. 39, 2008 , 772-778.

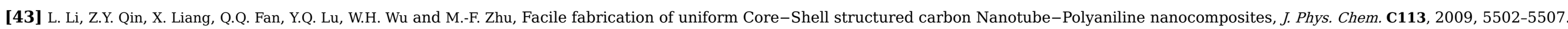

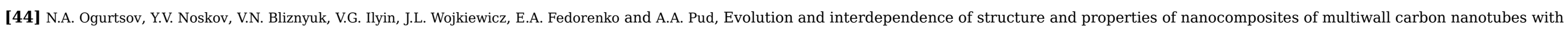
polyaniline, J. Phys. Chem. C120, 2016, 230-242.

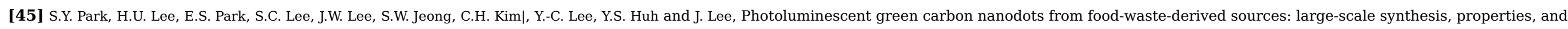
biomedical applications, ACS Appl. Mater. Interfaces 6, 2014, 3365-3370.

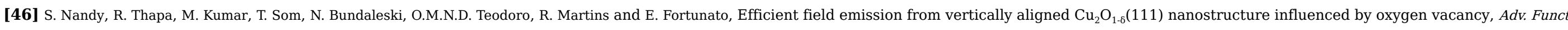
Mater. 25, 2015, 947-956.

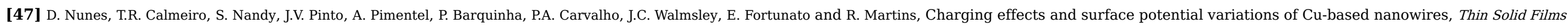
601, 2016, 45-53.

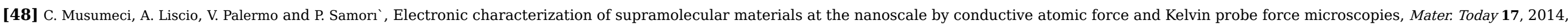
504-517.

[49] B. Li, X. Li, J. Zai and X. Qian, Facile synthesis of porous Zn-Sn-O nanocubes and their electrochemical performances, Nano-Micro Lett. 8 (2), 2016, 174-181.

[50] Q. Wu, Y. Xu, Z. Yao, A. Liu and G. Shi, Supercapacitors based on flexible graphene/polyaniline nanofiber composite films, ACS Nano 4, 2010, $1963-1970$.

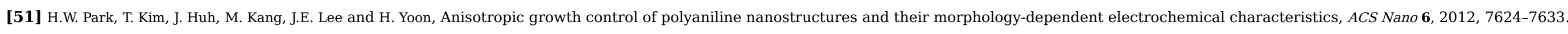

[52] E. Lust, G. Nurk, A. Janes, M. Arulepp, L. Permann, P. Nigu and P. Moller, Electrochemical properties of nanoporous carbon electrodes, Cond, Matter Phys. 5, $2002,307-327$.

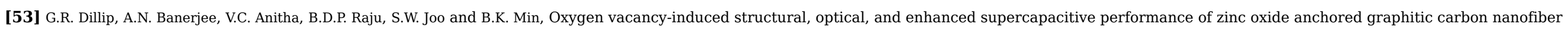
hybrid electrodes, ACS Appl. Mater. Interfaces 8, 2016, 5025-5039.

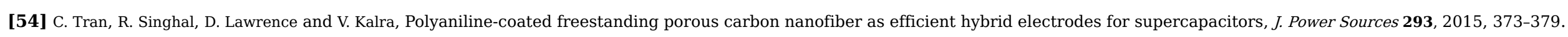

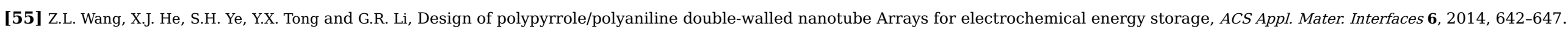

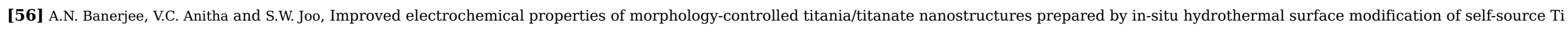
substrate for high-performance supercapacitors, Sci. Rep. 7 (20pp), 2017, 13227. 
[57] X. Lang, A. Hirata, T. Fujita and M. Chen, Nanoporous metal/oxide hybrid electrodes for electrochemical supercapacitors, Nat. Nanotechnol. 6, 2011 , 232-236.

[58] H. Wang and L. Pilon, Physical interpretation of cyclic voltammetry for measuring electric double layer capacitances, Electrochim. Acta 64, 2012, 130-139.

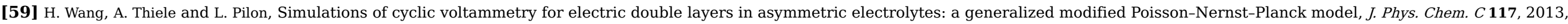
18286-18297.

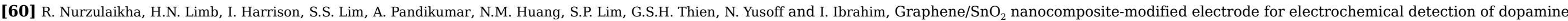
Sens. Biosensing Res. 5, 2015, 42-49.

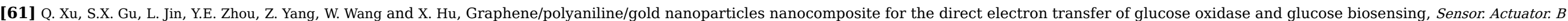
Chem. 190, 2014, 562-569.

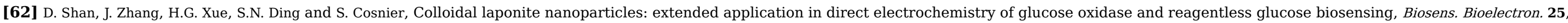
2010, 1427-1433.

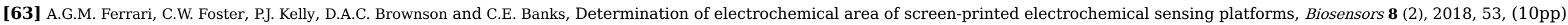

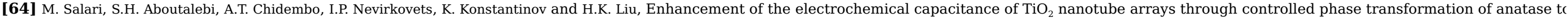
rutile, Phys. Chem. Chem. Phys. 14, 2012, 4770-4779.

[65] Y. Li, X. Zhao, P. Yu and Q. Zhang, Oriented arrays of polyaniline nanorods grown on graphite nanosheets for an electrochemical supercapacitor, Langmuir 29, 2013, 493-500.

[66] J. Ma, New Electrochemical Characterization Methods for Nanocomposite Supercapacitor Electrodes, arXiv:1406.0470v3 [cond-mat.mtrl-sci] 19 Apr 2016 (7pp).

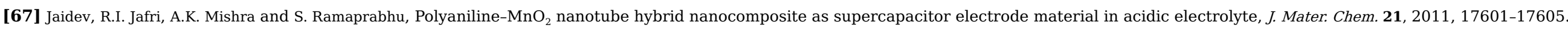

[68] H. Wang, J. Lin and Z.X. Shen, Polyaniline (PANi) based electrode materials for energy storage and conversion, J. Sci. Adv. Mater. Dev. 1, 2016, 225-255.

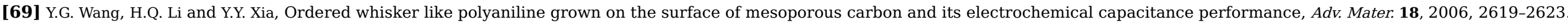

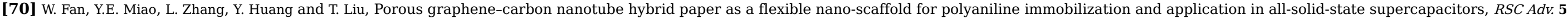
2015, 31064-31073.

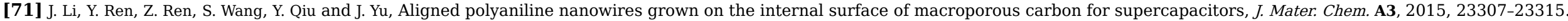

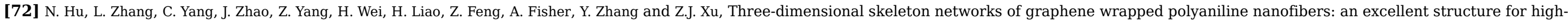
performance flexible solid-state supercapacitors, Sci. Rep. 6 (10pp), 2016, 19777.

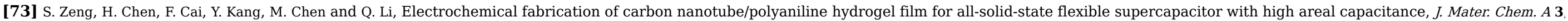
$2015,23864-23870$.

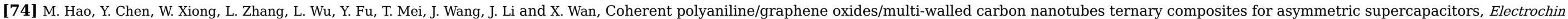
Acta 191, 2016, 165-172.

[75] C. Peng, S. Zhang, D. Jewell and G.Z. Chen, Carbon nanotube and conducting polymer composites for supercapacitors, Prog. Nat. Sci. 18, 2008, 777-788.

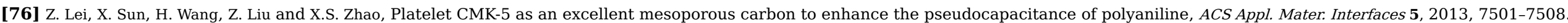

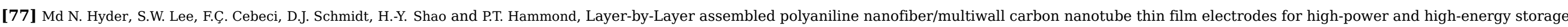


applications, ACS Nano 5, 2011, 8552-8561.

[78] H. Wang, F. Presuel and R.G. Kelly, Computational modeling of inhibitor release and transport from multifunctional organic coatings, Electrochim. Acta 49, 2004, 239-255

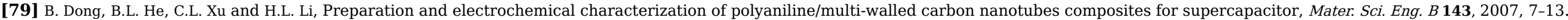

[80] F. Xu, G. Zheng, D. Wu, Y. Liang, Z. Li and R. Fu, Improving electrochemical performance of polyaniline by introducing carbon aerogel as filler, Phys. Chem. Chem. Phys. 12, 2010, $3270-3275$.

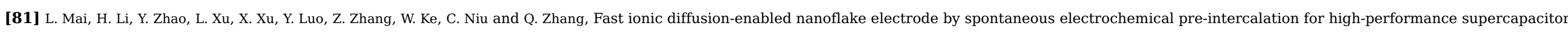
Sci. Rep. 3 (8pp), 2013, 1718.

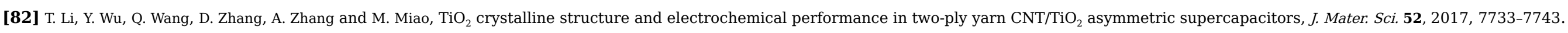

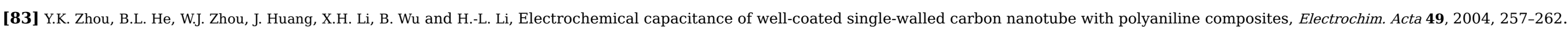

\section{Appendix A. Supplementary data}

The following is the Supplementary data to this article:

Multimedia Component 1

Multimedia component 1

alt-text: Multimedia component 1

\section{Graphical abstract}

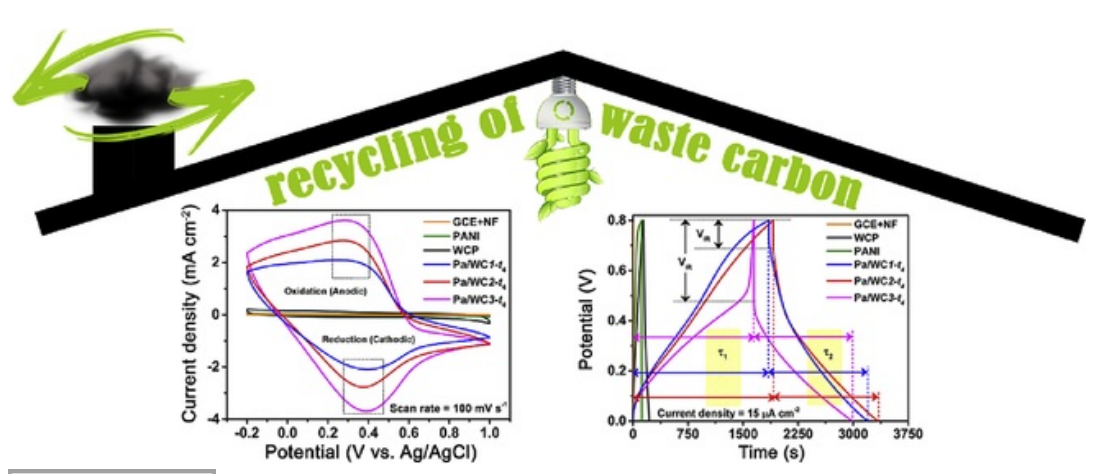

alt-text: Image 1

\section{Highlights}

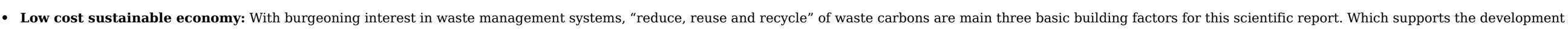
of next generation green-supercapacitors.

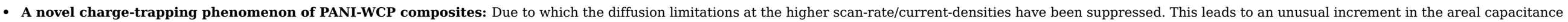
of the PANI-WCP composite electrochemical electrode at higher scan-rate/current densities, the reason of which is explained for the first time (to best of authors' knowledge) by a physico-chemical model. 


\section{Queries and Answers}

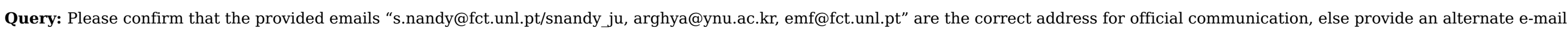
address to replace the existing one, because private e-mail addresses should not be used in articles as the address for communication.

Answer: All are correct.

Query: Have we correctly interpreted the following funding source(s) and country names you cited in your article: FCT, Portugal; FEDER; European Community H2020? Answer: Yes

Query: Highlights should only consist of "125" characters per bullet point, including spaces. The highlights provided are too long; please edit them to meet the requirement. Answer:

Attachments: Highlights.docx

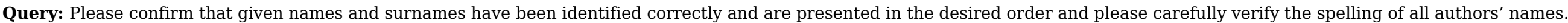
Answer: Yes

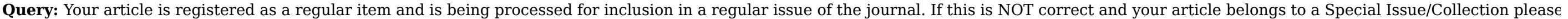
contact a.elumalai@elsevier.com immediately prior to returning your corrections.

Answer: Yes 